Working Paper 11-10

Economic Series

April, 2011
Departamento de Economía Universidad Carlos III de Madrid

Calle Madrid, 126

28903 Getafe (Spain)

Fax (34) 916249875

\title{
Oligopolistic Equilibrium and Financial Constraints
}

\author{
Carmen Beviá \\ Universitat Autònoma de Barcelona \\ Luis C. Corchón \\ Universidad Carlos III de Madrid \\ Yosuke Yasuda \\ National Graduate Institute for Policy Studies (GRIPS) \\ First version April 30th; 2008. This version April 4th, 2011.
}

\begin{abstract}
In this paper we present a model of oligopoly and financial constraints. We study allocations which are bankruptcy-free (BF) in the sense that no firm can drive another firm to bankruptcy without becoming bankrupt. We show how such allocations can be sustained as an equilibrium of a dynamic game. When there are two firms, all equilibria yield BF allocations. When there are more than two firms, allocations other than BF can be sustained as equilibria but in some cases the set of BF allocations still useful in explaining the shape of equilibrium set.
\end{abstract}

\footnotetext{
* This paper is a merger of two independent papers, "Oligopolistic Equilibrium and Bankruptcy" by Beviá and Corchón and "The Theory of Collusion under Financial Constraints" by Yasuda. The .rst two authors wish to thank to A. Brandenburger, L. Cabral, A. Daughety, M. Katz, F. Maniquet, J. Marín, E. Maskin, A. Nicolo, G. Pérez-Quiros, J. Reinganum, A. Wolinsky and audiences in seminars at NYU, Sydney U., PET 2009 (Galway), SED 2009 (Maastricht), M-SWET 2010 (Madrid) and IAE (Barcelona) for helpful suggestions. The third author wishes to thank to D. Abreu, E. Maskin, and especially P. Bolton for their guidance and to K. Bagwell, M. Kandori, I. Obara and S. Takahashi for useful comments. The first author acknowledges financial support from ECO2008-04756 (Grupo Consolidado-C), SGR2009-419, Barcelona GSE research network and MOVE where she is an affiliated researcher. The second author acknowledges financial support from SEJ2005-06167/ECON.
} 


\section{Introduction}

There is ample evidence that financial constraints play an important role in the behavior of firms (Bernanke and Gertler, 1989; Kiyotaki and Moore, 1997). We begin with the observation that the punishment for violation of a financial constraint must be severe or otherwise firms would default all the time. Suppose that the punishment is so severe that firms violating financial constraints loose the ability to compete and, in fact, disappear (Sharfstein and Bolton, 1990). Firms might then have incentives to take actions that will make it impossible for competitors to fulfill financial constraints in the hope to get rid of them.

In this paper we provide a model of oligopolistic interaction among firms when they fully take into account the financial constraints of all other firms and not only their own financial constraints. We model these financial constraints by assuming that profits must be greater than or equal to an exogenously given value. When profits are below this value, we will say that this firm is bankrupted. Our aim is to offer a dynamic theory of oligopoly in which firms can bankrupt each other. This theory is in sharp contrast to the standard theory of repeated games in which bankruptcy considerations are not considered.

Our first step is to define the set of actions that are bankruptcy-free (BF in the following). This set of actions has two properties. On the one hand, profits are not less than some exogenously given value for any firm. On the other hand, no firm can be pushed below this value by any action of another firm that obtains profits in excess of this value. The concept of BF captures the opportunities for ruining other players that are not captured by standard concepts such as Cournot equilibrium. We show that such a concept plays an important role in shaping the set of long-run equilibria in an industry.

Our second step consists of characterizing the set of BF actions under alternative assumptions. For simplicity, we confine ourselves to the case in which the product is homogeneous. ${ }^{1}$ In the case in which average costs are non-decreasing, we show that a large number of output vectors are BF (Proposition 1). For instance, when all firms have constant average costs and all firms are identical, any output vector yielding non-negative profits is BF (Example 1). When there are two firms with identical increasing average costs, the set of BF output vectors is a square (Example 2). By contrast, when average costs are decreasing, BF output vectors are either such that all firms

\footnotetext{
${ }^{1}$ We note that some forms of product heterogeneity are equivalent to product homogeneity.
} 
have zero profits and further increases in output produce negative profits or those in which only one firm is active (Proposition 2 and Example 3). Thus, BF captures the idea, present in many informal discussions, that markets with non-decreasing costs and markets with decreasing costs are fundamentally different. In our case this is because under increasing costs, ruining a competitor requires an increase in the average cost that makes the attacking firm weaker. Under decreasing costs, ruining a competitor implies a decrease in average costs that make the attacking firm even stronger.

Our next step is to consider a dynamic game in which firms can be bankrupted and accordingly they might disappear. This setup is not a repeated game because the game in each period depends on the strategies chosen in the past. Rather it is a special case of a stochastic game (Shapley, 1953; Neyman and Sorin, 2003) in which transition probabilities are zero or one (Masso and Neme, 1996). Such games are called Dynamic Games. To simplify our task we make two assumptions: profits cannot be transferred from one period to the next and the financial constraint in each period requires that profits must be non-negative in each period. The second assumption is innocuous because it entails just a numerarization of profits. However, the first assumption is certainly not innocuous and is discussed later on.

We first note that if the Nash equilibrium (NE) corresponding to the static game is BF, this allocation can be supported as a Subgame Perfect NE (SPNE). Next, we show for duopoly that when the discount rate is sufficiently close to one, any NE must yield BF allocations (Proposition 3). Unfortunately, this result cannot extended to three players (Example 4). Given this result, we study equilibria by considering separately the cases in which average costs are increasing and decreasing. ${ }^{2}$

Consider first increasing average costs. The concept of minimax payoff plays an important role here (as in the folk theorem for repeated games) but it has to be adapted to the case in which actions are constrained to be BF. We refer to this adaptation as the minimax BF payoff. We show that any $\mathrm{BF}$ action profile that gives a payoff greater than the minimax BF payoff can be supported as an SPNE for a discount factor close to one (Proposition 5). Furthermore, payoffs less than the minimax BF payoff cannot be sustained in any SPNE (Proposition 4).

Finally, we tackle the case of decreasing average costs. We show that BF action profiles with at

\footnotetext{
${ }^{2}$ The case of constant returns is a limit case between increasing a decreasing average costs and is briefly considered.
} 
least two active firms cannot be supported by an NE and we give conditions under which BF action profiles with only one active firm can be supported as NE (Proposition 7). We also show that action profiles in which all firms produce a positive quantity cannot be supported as NE (Proposition 8). However, there are SPNE with all but one active firms (Example 8).

Our results show that introduction of a financial constraint affects the equilibrium strategies of firms and, in some cases, substantially reduces the set of equilibrium payoffs. For example, Proposition 3 implies that the folk theorem of repeated games does not hold in our setup. Moreover, playing the Cournot equilibrium in each period and the standard stick-and-carrot punishments need not be an NE either. This shows that our approach has important implications for collusion, merger and thus, anti-trust policy.

We end this introduction with a preliminary discussion of the literature (see more on this in the final section). Although a number of papers demonstrate that the financial structure does affect market outcomes in oligopoly, most previous studies adopt either static or two-stage models. Kawakami and Yoshida (1997) and Spagnolo (2000) are the only two exceptions. Both papers make use of repeated games like ours. The former incorporates a simple exit constraint into the repeated prisoners' dilemma. In their model, each firm must exit from the market no matter how it plays if the rival deviates over a certain period of time. Fixing the length of such an endurable period of time intrinsic to each firm, they show that predation can occur when a discount factor becomes large. The latter study examines the role of stock options in repeated Cournot games. In this model, unlike standard repeated games, firms do not necessarily maximize average discounted profits because stock options affect managers' incentives. Considering this effect, Spagnolo shows that collusion is easily achieved. Finally, our approach might provide support to the notion that firms may engage in predatory activities when pursuing profit maximization. Standard explanations of this behavior are based on incomplete information (Milgrom and Roberts, 1982), the learning curve (Cabral and Riordan, 1994) or firms playing an attrition game (Roth, 1996). In our model, firms have complete information, the technology is fixed and firms play standard quantity-setting games. However, our concept of $\mathrm{BF}$ focuses on allocations in which predation is impossible. Predation in equilibrium might occur when there are sunk costs. ${ }^{3}$

\footnotetext{
${ }^{3}$ An example is available under request.
} 


\section{Bankruptcy-Free Allocations}

There are $n$ firms. Each firm, say $i$, has an action space denoted by $S_{i}$. An action could be an output, a price, a supply function, etc. An action profile is a vector of actions $s \in \Pi_{i=1}^{n} S_{i}$. Let $s_{-i}=\left(s_{1}, . ., s_{i-1}, s_{i+1}, . ., s_{n}\right)$, and $\left(\hat{s}_{i}, s_{-i}\right)=\left(s_{1}, . ., s_{i-1}, \hat{s}_{i}, s_{i+1}, . ., s_{n}\right)$. The profit of firm $i$ depends on the action profile and is denoted by $\pi_{i}(s)$.

Definition 1. An action profile $\hat{s}=\left(\hat{s}_{1}, \hat{s}_{2}, \ldots ., \hat{s}_{n}\right)$ is bankruptcy-free $(B F)$ if:

a) $\pi_{i}(\hat{s}) \geq 0$, for all $i \in\{1, . ., n\}$.

b) For all $s_{j}$ such that $\pi_{j}\left(\hat{s}_{-j}, s_{j}\right) \geq 0, \pi_{i}\left(\hat{s}_{-j}, s_{j}\right) \geq 0$ for all $i \neq j$.

In other words, a profile of actions is BF if it yields non negative profits for all firms and no firm can change its action, obtain non-negative profits and ruin other firm. Note that if firms are required to make $v_{i}$ profits to avoid bankruptcy, we can define a new profit function as $\pi_{i}^{\prime}(s) \equiv \pi_{i}(s)-v_{i}$ and redefine $\mathrm{BF}$ with respect to this new profit function.

To grasp the implications of $\mathrm{BF}$ on economic environments, in this section we study the set of $\mathrm{BF}$ actions in the quantity-setting model, one of the most popular models in industrial organization.

Let $s_{i}=x_{i}$ where $x_{i} \in \mathbb{R}_{+}$denotes the quantity set by firm $i$. Let $x=\left(x_{1}, . ., x_{n}\right)$ be a quantity profile and $p_{i}(x)$ be the inverse demand function for firm $i$ assumed to be strictly decreasing in $x_{i}$. Let $c_{i}\left(x_{i}\right)$ be the cost of producing $x_{i}$ for firm $i$. The average cost of producing $x_{i}$ is denoted by $A V C_{i}\left(x_{i}\right)$. Unless stated specifically we will assume that $c_{i}(0)=0$. We assume that profits for any firm are a concave function of its own output when this output is positive.

Spence (1980) observed that some models of product heterogeneity can be transformed into the model of a single homogeneous product. Given this observation we will concentrate on the case of product homogeneity. If a firm is producing a positive quantity we call it an active firm. Otherwise it is an inactive firm. Clearly, an action profile with all inactive firms and no sunk costs is $B F$. In what follows we concentrate in the characterization of $B F$ action profiles with at least an active firm.

We start by characterizing the set of BF action profiles for $n$ firms with non-decreasing average costs. We assume that for all $i$, and for all $x_{-i}$, there exist $\bar{x}_{i} \neq 0$ such that $\pi_{i}\left(x_{-i}, \bar{x}_{i}\right)=0$. To build intuition, we first consider two examples.

Example 1. Suppose there are two firms whose average cost is constant with inverse demand 
$p\left(x_{1}, x_{2}\right)=2-x_{1}-x_{2}$. First, set $A V C_{1}=1$ and $A V C_{2}=1.5$. In Figure 1, the set of allocations in which firm 1 (resp. 2) has non negative profits is the triangle with vertex $(0,1,1)$ plus the vertical axis (resp. $(0,0.5,0.5)$ plus the horizontal axis). The set of BF action profiles is any pair $\left(\hat{x}_{1}, \hat{x}_{2}\right)$ with $0 \leq \hat{x}_{1} \leq 1$ and $\hat{x}_{2}=0$. If the two firms are equal with $A V C_{1}=A V C_{2}=1$, the set of $B F$ allocations is the triangle with vertex $(0,1,1)$.

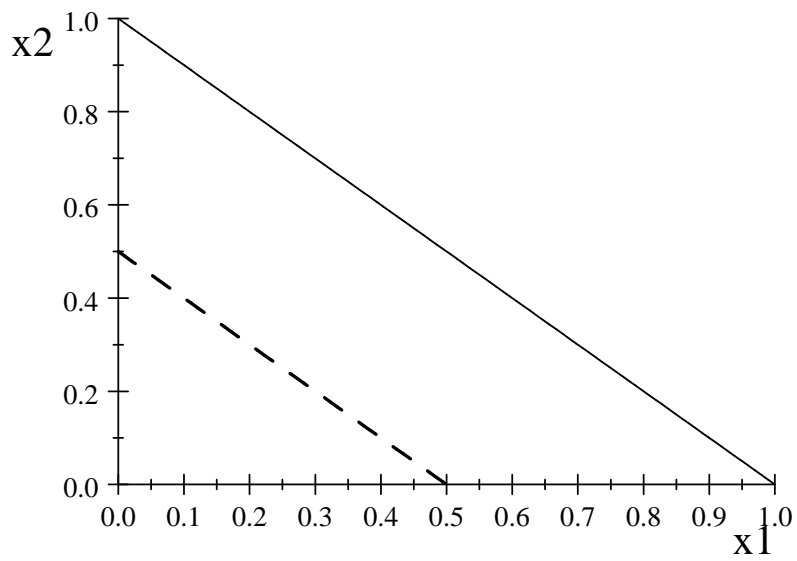

Figure 1

It is easy to see that this example can be generalized to more than two firms and any continuous inverse demand. In this case, only the firm with the lowest average cost can be active in a $\mathrm{BF}$ allocation. Let us consider now the case in which average costs are increasing.

Example 2. Suppose there are two firms with identical increasing average costs $c_{i}\left(x_{i}\right)=0.5 x_{i}^{2}$, $i=1,2$. The inverse demand function is $p\left(x_{1}, x_{2}\right)=\left(10-x_{1}-x_{2}\right)$. Thus, $\pi_{i}\left(x_{1}, x_{2}\right)=(10-$ $\left.x_{1}-x_{2}\right) x_{i}-0.5 x_{i}^{2}, i=1,2$. In Figure 2, the area where $x_{2} \leq 10-1.5 x_{1}$ plus the vertical axis (resp. $x_{1} \leq 10-1.5 x_{2}$ plus the horizontal axis) is the locus of points in which firm 1 (resp. 2) has non-negative profits. Both lines intersect at $(4,4)$. Starting from any action profile in the square $[0,4] \times[0,4]$, we see that a unilateral change in output by, say, firm 1 cannot drive firm 2 to bankruptcy without firm 1 being bankrupt itself. However a point such as $(1,5)$ is not BF because firm 1 can produce output of 3 and drive firm 2 to bankruptcy without being bankrupt itself. 


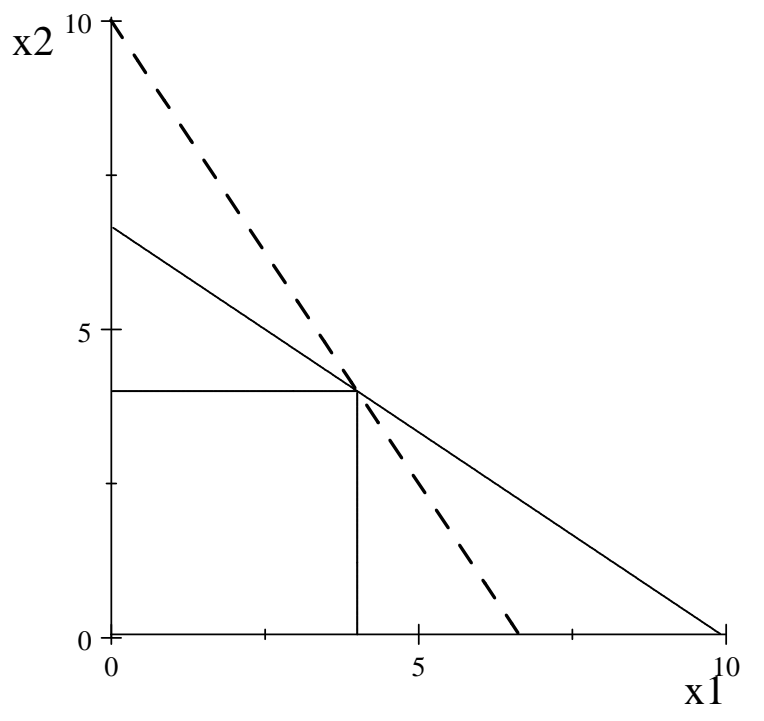

Figure 2

Again the above example can be generalized to two firms with continuous increasing average costs and facing a continuous and decreasing inverse demand function whenever $\left(\hat{x}_{1}, \hat{x}_{2}\right)$ such that $\pi_{i}\left(\hat{x}_{1}, \hat{x}_{2}\right)=0$, and $\hat{x}_{i} \neq 0, i=1,2$, exist. In these cases, an action profile $\left(x_{1}, x_{2}\right)$ is $B F$ if and only if $x_{i} \leq \hat{x}_{i}$ for all $i \in\{1,2\}$ and $\pi_{i}\left(x_{1}, x_{2}\right) \geq 0$.

We are now prepared for our first characterization that covers all the above cases.

Proposition 1. Let $n$ firms have non-decreasing average costs. An action profile $x=\left(x_{1}, \ldots, x_{n}\right)$ is $B F$ if $\pi_{i}(x) \geq 0$ for all $i \in N$, and any of the following conditions hold.

(i) All firms have the same average cost, that is, $A V C_{j}\left(x_{j}\right)=A V C_{k}\left(x_{k}\right)$ for all $j, k$; or

(ii) For all active firms $j, k$ if $A V C_{j}\left(x_{j}\right)<A V C_{k}\left(x_{k}\right)$, firm $j$ can always increases its output in a way that matches the average cost of firm $k$, retaining non negative profits. That is, there is $\tilde{x}_{j}$ such that $A V C_{j}\left(\tilde{x}_{j}\right)=A V C_{k}\left(x_{k}\right)$, and $p\left(\sum_{i \neq j} x_{i}+\tilde{x}_{j}\right)-A V C_{j}\left(\tilde{x}_{j}\right) \geq 0$.

If a firm $j$ is inactive, then for all $x_{j}^{\prime} \neq 0$ such that $\pi_{j}\left(x_{-j}, x_{j}^{\prime}\right)=0, A V C_{j}\left(x_{j}^{\prime}\right)>A V C_{k}\left(x_{k}\right)$ for all active firms $k$.

Proof. It is obvious that the action profiles described in $(i)$ are $B F$. For the action profiles described in $(i i)$, since the average cost is non-decreasing it is obvious that no firm with positive production can drive a firm with lower average cost to bankruptcy. It is also obvious that no inactive firm can enter the market and drive the active firms to bankruptcy. We also show that 
it is not possible for a firm with positive production to drive a firm with higher average cost to bankruptcy. Let $\bar{x}_{j}$ be such that

$$
p\left(\sum_{i \neq j} x_{i}+\bar{x}_{j}\right) \geq A V C_{j}\left(\bar{x}_{j}\right)
$$

If $A V C_{j}\left(\bar{x}_{j}\right) \geq A V C_{k}\left(x_{k}\right)$, since the average cost is non-decreasing, then $p\left(\sum_{i \neq j} x_{i}+\bar{x}_{j}\right)-$ $A V C_{k}\left(x_{k}\right) \geq 0$. If $A V C_{j}\left(\bar{x}_{j}\right)<A V C_{k}\left(x_{k}\right)$, then $A V C_{j}\left(\bar{x}_{j}\right)<A V C_{j}\left(\tilde{x}_{j}\right)$, and since average cost is non-decreasing, $\bar{x}_{j}<\tilde{x}_{j}$. Then $p\left(\sum_{i \neq j} x_{i}+\bar{x}_{j}\right)>p\left(\sum_{i \neq j} \tilde{x}_{i}+\tilde{x}_{j}\right) \geq A V C_{j}\left(\tilde{x}_{j}\right)=A V C_{k}\left(x_{k}\right)$. Therefore, for all $k \neq j$, with higher average cost $p\left(\sum_{i \neq j} x_{i}+\bar{x}_{j}\right)-A V C_{k}\left(x_{k}\right) \geq 0$.

Finally, we show that any other action profile cannot be $B F$.

Let $x^{\prime}=\left(x_{1}^{\prime}, \ldots, x_{n}^{\prime}\right)$ be such that $\pi_{i}\left(x^{\prime}\right) \geq 0$ for all $i \in N$, and suppose that there are two active firms, $j$ and $k$, with $A V C_{j}\left(x_{j}^{\prime}\right)<A V C_{k}\left(x_{k}^{\prime}\right)$, and such that, for $\tilde{x}_{j}$ with $A V C_{j}\left(\tilde{x}_{j}\right)=$ $A V C_{k}\left(x_{k}^{\prime}\right), p\left(\sum_{i \neq j} x_{i}^{\prime}+\tilde{x}_{j}\right)-A V C_{j}\left(\tilde{x}_{j}\right)<0$. Since $\pi_{j}\left(x^{\prime}\right)>0$ and the price-average cost difference is decreasing, firm $j$ can decrease production and make cero profits. That is, there is $\bar{x}_{j}<\tilde{x}_{j}$ such that $p\left(\sum_{i \neq j} x_{i}^{\prime}+\bar{x}_{j}\right)-A V C_{j}\left(\bar{x}_{j}\right)=0$. Since $A V C_{j}\left(\bar{x}_{j}\right)<A V C_{j}\left(\tilde{x}_{j}\right)=A V C_{k}\left(x_{k}^{\prime}\right)$, $p\left(\sum_{i \neq j} x_{i}^{\prime}+\bar{x}_{j}\right)-A V C_{j}\left(\bar{x}_{j}\right)>p\left(\sum_{i \neq j} x_{i}^{\prime}+\bar{x}_{j}\right)-A V C_{k}\left(x_{k}^{\prime}\right)$, which implies that firm $j$ can drive firm $k$ to bankruptcy.

Let $x^{\prime}=\left(x_{1}^{\prime}, \ldots, x_{n}^{\prime}\right)$ be such that $\pi_{i}\left(x^{\prime}\right) \geq 0$ for all $i \in N$, and suppose that there are two active firms, $j$ and $k$, with $A V C_{j}\left(x_{j}^{\prime}\right)<A V C_{k}\left(x_{k}^{\prime}\right)$, and such that firm $j$ can never match the average cost of firm $k$, that is, for all $\tilde{x}_{j}, A V C_{j}\left(\tilde{x}_{j}\right)<A V C_{k}\left(x_{k}^{\prime}\right)$. Let $\bar{x}_{j}$ be such that $p\left(\sum_{i \neq j} x_{i}^{\prime}+\bar{x}_{j}\right)-A V C_{j}\left(\bar{x}_{j}\right)=0$. By our assumptions $\bar{x}_{j}$ exist, and since $A V C_{j}\left(\bar{x}_{j}\right)<A V C_{k}\left(x_{k}^{\prime}\right)$, firm $k$ is bankrupt.

Finally, if for an inactive firm $k$ there is an $\bar{x}_{k} \neq 0$ such that $A V C_{j}\left(x_{j}^{\prime}\right)>A V C_{k}\left(\bar{x}_{k}\right)$ and $p\left(\sum_{i \neq k} x_{i}^{\prime}+\bar{x}_{k}\right)=A V C_{j}\left(x_{j}^{\prime}\right)$, firm $k$ can increase his production above $\bar{x}_{k}$ and make firm $j$ bankrupt while retaining positive profits.

We now consider the case of decreasing average costs. As before, to build intuition we first consider an example.

Example 3. Suppose there are two firms with cost functions $c_{i}\left(x_{i}\right)=88+10 x_{i}$, for all $x_{i} \neq 0$, and $c_{i}(0)=0$. Let $p\left(x_{1}+x_{2}\right)=100-x_{1}-x_{2}$. The area in which both firms have positive profits is $x_{2} \leq 90-x_{1}-88 / x_{1}$ (continuous line in Figure 3) and $x_{1} \leq 90-x_{2}-88 / x_{2}$ (dotted line in Figure 3). Point $B=\left(B_{1}, B_{2}\right)=(44,44)$ is a $B F$ action profile such that $\pi_{i}\left(\hat{x}_{1}, \hat{x}_{2}\right)=0$. Note that when $x_{1}=x_{2}=1$, both agents also have zero profits, but this action profile is not BF because, say, 
firm 1 can produce output of 88, obtaining zero profits and bankrupting firm 2. Also note that all action profiles such that $x_{2}=0, x_{1} \geq B_{1}$ and $\pi_{1}\left(x_{1}, 0\right) \geq 0$, or $x_{1}=0, x_{2} \geq B_{2}$ and $\pi_{2}\left(0, x_{2}\right) \geq 0$ are BF. It is easy to see in Figure 3 that no other action profile can be BF.

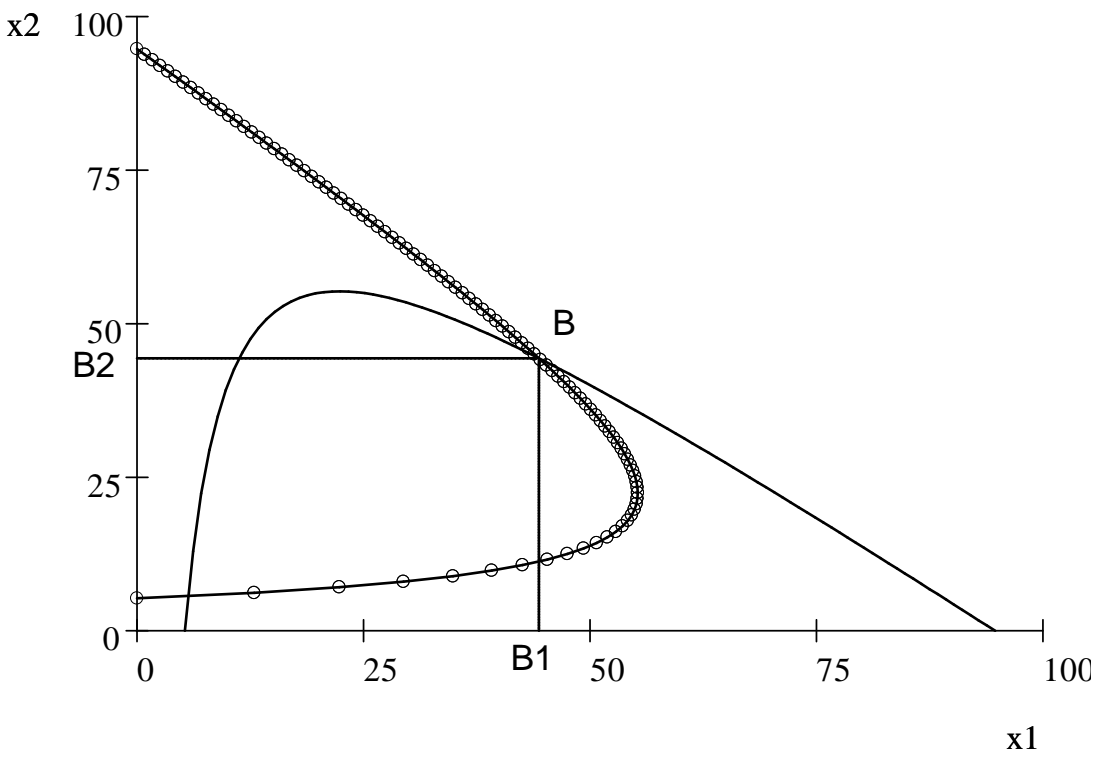

Figure 3

Our next result characterizes the set of BF allocations under decreasing average costs. We restrict our attention to economies that satisfy the following assumption.

Assumption 1. The inverse demand function is strictly decreasing and $\lim _{x \rightarrow \infty} p(x)=0$. Each firm has decreasing average cost with $\lim _{x \rightarrow \infty} A V C_{i}(x)=a_{i}>0$, and there is $\left(x_{1}, . ., x_{n}\right)$ such that $p\left(x_{1}+. .+x_{n}\right)>A V C_{i}\left(x_{i}\right)$ for all $i \in\{1, . ., n\}$.

Assumption 1 guarantees the existence and uniqueness of an action profile $\left(\hat{x}_{1}, . ., \hat{x}_{n}\right)>>(0, . ., 0)$ such that $\pi_{j}\left(\hat{x}_{1}, . ., \hat{x}_{n}\right)=0$, and $\partial \pi_{j}\left(\hat{x}_{1}, . ., \hat{x}_{n}\right) / \partial x_{j}<0$ for all $j \in\{1, . ., n\}$.

We will use this action profile $\left(\hat{x}_{1}, . ., \hat{x}_{n}\right)$ in the following proposition.

Proposition 2. Under Assumption 1, an action profile $x=\left(x_{1}, . ., x_{n}\right)$ is $B F$ if $\pi_{i}(x) \geq 0$ for all $i \in N$, and any of the following conditions hold.

(i) There is only one active firm, $i$. For this firm $x_{i} \geq \hat{x}_{i}$, 
(ii) There are at least two active firms. For all active firms, $\pi_{i}\left(x_{1}, . ., x_{n}\right)=0$ and $\partial \pi_{i}\left(x_{1}, . ., x_{n}\right) / \partial x_{i}<$ 0 ; for all inactive firms, $\pi_{i}\left(\bar{x}_{i}, x_{-i}\right)<0$ for all $\bar{x}_{i}>0$.

Proof. Step 1. We show first that no action profile $\left(x_{1}, \ldots, x_{n}\right)$ such that at least two firms are active and at least one has strictly positive profits is $B F$.

Without lost of generality, suppose that firm 1 and 2 are active, and $\pi_{1}\left(x_{1}, . ., x_{n}\right)>0$. If $\pi_{2}\left(x_{1}, . ., x_{n}\right)=0$, then $A V C_{1}\left(x_{1}\right)<A V C_{2}\left(x_{2}\right)$. If $\pi_{2}\left(x_{1}, . ., x_{n}\right)>0$, suppose w.l.o.g. that $A V C_{1}\left(x_{1}\right) \leq A V C_{2}\left(x_{2}\right)$. Let $y>x_{1}$ be such that $\pi_{1}\left(y, x_{2}, . ., x_{n}\right)=0$; by Assumption $1, y$ exist. If firm 1 increases its production from $x_{1}$ to $y$, the price will be equal to the average cost of $y$, and since the average cost is decreasing, $A V C_{1}(y)<A V C_{1}\left(x_{1}\right)$. Since $A V C_{1}\left(x_{1}\right) \leq A V C_{2}\left(x_{2}\right)$, firm 2 is bankrupt.

Step 1 tells us that only action profiles such that all firms have zero profits or action profiles for which only one firm has positive profits and all others are not active can be $B F$.

Step 2. We show that an action profile $\left(x_{1}, \ldots, x_{n}\right)$, such that for all $i \in\{1, \ldots, n\}, \pi_{i}\left(x_{1}, . ., x_{n}\right)=0$, with at least two active firms and such that $\partial \pi_{i}\left(x_{1}+. .+x_{n}\right) / \partial x_{i} \geq 0$ for some of the active firms, is not $B F$.

Suppose that the firm with the above characteristics is firm 1. Since $\partial \pi_{i}\left(x_{1}+. .+x_{n}\right) / \partial x_{i} \geq 0$, firm 1 can slightly increase its output and obtain non negative profits. Since the price will decrease, all other active firms will be bankrupt.

Step 3. We show that an action profile $\left(x_{1}, \ldots, x_{n}\right)$, such that for all $i \in\{1, \ldots, n\}, \pi_{i}\left(x_{1}, . ., x_{n}\right)=0$, with at least two active firms such that for all active firms $\partial \pi_{i}\left(x_{1}+. .+x_{n}\right) / \partial x_{i}<0$, and such that for at least one inactive firm $j$ there exist $\bar{x}_{j}>0$ such that $\pi_{j}\left(\bar{x}_{j}, x_{-j}\right) \geq 0$, cannot be $B F$.

If this were the case, the inactive firm $j$ could produce $\bar{x}_{j}$ and retain non negative profits. Since the price will decrease, all active firms will be bankrupted.

Step 4. We show that the action profiles with at least two active firms such that for all $i \in$ $\{1,2, \ldots, n\}, \pi_{i}\left(x_{1}, . ., x_{n}\right)=0$, for all active firms $\partial \pi_{i}\left(x_{1}, . ., x_{n}\right) / \partial x_{i}<0$, and for all inactive firms $\pi_{i}\left(\bar{x}_{i}, x_{-i}\right)<0$ for all $\bar{x}_{i}>0$, are $B F$.

Clearly, inactive firms cannot increase production without bankrupting themselves. Active firms can only bankrupt other active firms by increasing their production, but since $\partial \pi_{i}\left(x_{1}, . ., x_{n}\right) / \partial x_{i}<0$ and profits are concave, this will also bankrupt them.

Step 5. We show that an action profile with only one active firm and such that $x_{i}<\hat{x}_{i}$ is not $B F$. 
Suppose that an inactive firm $j$ produces $x_{j}^{*} \neq 0$ such that $x_{j}^{*}+x_{i}=\hat{x}_{1}+\ldots+\hat{x}_{n}$. Since $x_{i}<\hat{x}_{i}$, $x_{j}^{*}>\hat{x}_{j}$. Since average cost is decreasing $A V C_{j}\left(x_{j}^{*}\right)<A V C_{j}\left(\hat{x}_{j}\right)$, and thus $\pi_{j}\left(0, . ., x_{i}, 0, . ., x_{j}^{*}\right)>0$. Since $p\left(x_{j}^{*}+x_{i}\right)=p\left(\hat{x}_{1}+. .+\hat{x}_{n}\right)$, and $x_{i}<\hat{x}_{i}, p\left(x_{j}^{*}+x_{i}\right)-A V C_{i}\left(x_{i}\right)<p\left(\hat{x}_{1}+. .+\hat{x}_{n}\right)-A V C_{i}\left(\hat{x}_{i}\right)=0$, which implies that firm $i$ is bankrupt.

Step 6. Finally, we show that action profiles with only one active firm and such that $x_{i} \geq \hat{x}_{i}$ are $B F$.

We show that no inactive firm $j$ can bankrupt the active firm $i$.For this it is enough to show that for all $x_{j}^{*}$ such that $\pi_{j}\left(0, . ., x_{i}, . ., x_{j}^{*}, . ., 0\right) \geq 0$, then $\pi_{i}\left(0, . ., x_{i}, . ., x_{j}^{*}, . ., 0\right) \geq 0$.

Suppose first that $j$ is such that $x_{i}<\sum_{k \neq j} \hat{x}_{k}$.

If $x_{j}^{*}<\hat{x}_{j}$, then $x_{i}+x_{j}^{*}<\sum_{k} \hat{x}_{k}$. Since $x_{i} \geq \hat{x}_{i}, p\left(x_{i}+x_{j}^{*}\right)-A V C_{i}\left(x_{i}\right)>p\left(\sum_{k} \hat{x}_{k}\right)-A V C_{i}\left(\hat{x}_{i}\right)=0$, which implies that $\pi_{i}\left(0, . ., x_{i}, . ., x_{j}^{*}, . ., 0\right) \geq 0$.

If $x_{j}^{*}>\hat{x}_{j}$, suppose that $\pi_{i}\left(0, . ., x_{i}, . ., x_{j}^{*}, . ., 0\right)=p\left(x_{i}+x_{j}^{*}\right)-A V C_{i}\left(x_{i}\right)<0=p\left(\sum_{k} \hat{x}_{k}\right)-A V C_{i}\left(\hat{x}_{i}\right)$. Since $x_{i}>\hat{x}_{i}, p\left(x_{i}+x_{j}^{*}\right)<p\left(\sum_{k} \hat{x}_{k}\right)$. Thus, since $p$ is decreasing, $x_{i}+x_{j}^{*}>\sum_{k} \hat{x}_{k}$. Therefore, there exist $t>0$ such that $x_{i}+x_{j}^{*}=\hat{x}_{j}+t+\sum_{k \neq j} \hat{x}_{k}$. Since profits are concave for strictly positive values of $x_{j}$, and $\pi_{j}\left(\hat{x}_{1}, . ., \hat{x}_{n}\right)=0$ with $\partial \pi_{j}\left(\hat{x}_{1}, . ., \hat{x}_{n}\right) / \partial x_{j} \leq 0$, then $\pi_{j}\left(0, . ., x_{i}, . ., x_{j}^{*}, . ., 0\right)<0$, which contradicts the hypothesis. Thus, $\pi_{i}\left(0, . ., x_{i}, . ., x_{j}^{*}, . ., 0\right) \geq 0$.

Suppose that $j$ is such that $x_{i} \geq \sum_{k \neq j} \hat{x}_{k}$.

First, we show that $x_{j}^{*} \leq \hat{x}_{j}$. If $x_{j}^{*}>\hat{x}_{j}$, given that $x_{i} \geq \sum_{k \neq j} \hat{x}_{k}$, then $x_{i}+x_{j}^{*}>\sum_{k=1}^{n} \hat{x}_{k}$; but by the definition of $\left(\hat{x}_{1}, . ., \hat{x}_{n}\right)$ and given that profits are concave for strictly positive values of $x_{j}, \pi_{j}\left(x_{j}^{*}, x_{-j}\right)$ will be negative. Thus $x_{j}^{*} \leq \hat{x}_{j}$. Therefore $A V C_{j}\left(x_{j}^{*}\right) \geq A V C_{j}\left(\hat{x}_{j}\right)=$ $p\left(\hat{x}_{1}+. .+\hat{x}_{n}\right)$ which implies that $p\left(\hat{x}_{1}+. .+\hat{x}_{n}\right) \leq p\left(x_{i}+x_{j}^{*}\right)$, and given that $x_{i} \geq \hat{x}_{i}$, it follows that $p\left(x_{i}+x_{j}^{*}\right)-A V C_{i}\left(x_{i}\right) \geq p\left(\hat{x}_{1}+. .+\hat{x}_{n}\right)-A V C_{i}\left(\hat{x}_{i}\right)=0$.

The above steps prove that the $B F$ action profiles are those described in $(i)$ and $(i i)$

Notice that the point $\left(B_{1}, B_{2}\right)$ in Example 3 corresponds to the outputs described in part (ii) in Proposition 2. The outputs in part (i) correspond to those in Example 3 in which one of the firms is inactive and the other firm produces, at least, the corresponding $B_{i}$.

Proposition 2 can be easily adapted to the case in which firms have sunk costs, i.e. $c(0)=k$. In this case in any $B F$ action profile all firms must be active, otherwise they are bankrupt. Therefore the set of $B F$ action profiles reduces to those in part (ii) in Proposition 2 (point $B$ in Figure 3 ). 


\section{Long-Run Competition with Bankruptcy}

In this section we consider a dynamic game with an infinite horizon in which firms can be bankrupt. We identify conditions under which such dynamic competition leads to BF allocations as defined in the previous section.

Each firm, say $i$, has an action space denoted by $S_{i}$ that can be interpreted as the output, price, etc. set by this firm. In each period, say $t$, each firm chooses an action $s_{i}^{t}$.

The payoffs obtained by firm $i$ in period $t$ are denoted by $\pi_{i}\left(s^{t}\right)$ where $s^{t} \in \times_{i=1}^{n} S_{i} \equiv S$ is the tuple of actions played in period $t=1,2, \ldots, \tau, \ldots$. Firms cannot accumulate profits, and hence they become bankrupt as long as they have negative profits in a period. If a firm disappears from the game in subsequent periods, this firm is supposed to take an action $\bar{s}_{i}$ which corresponds to no action (i.e. zero output or a price for which demand is always zero). Formally, if $\pi_{i}\left(s^{t}\right)<0$, $\pi_{i}\left(s^{t+r}\right)=0$, and $s_{i}^{t+r}=\bar{s}_{i}$ for all $r=1,2, \ldots$, . Let $\delta \in[0,1]$ be the common discount factor. Payoffs for the game for firm $i$ are $P_{i}=(1-\delta) \sum_{t=0}^{\infty} \delta^{t} \pi_{i}\left(s^{t}\right)$. The continuation payoff in period $t$ is given by $P_{i}^{t}=(1-\delta) \sum_{s=0}^{\infty} \delta^{s} \pi_{i}\left(s^{t+s}\right)$.

We start this section with a very simple observation. Let $\left(s_{1}^{N}, s_{2}^{N}, \ldots \ldots . s_{n}^{N}\right)$ be a list of actions that is an NE of the static game, and $\pi_{i}^{N}$ be the profits obtained by $i$ in an NE of the one-shot game. Then we have the following:

Observation. Assume that the actions corresponding to a one shot NE are $B F$. Then:

(i) The allocation corresponding to this NE can be sustained as an SPNE of the dynamic game for any $\delta$.

(ii) When $\delta$ tends to 1 , any sequence of action profiles that are BF and yield profits larger than $\pi_{i}^{N}$ can be sustained as an SPNE.

Proof. (i) From Fudenberg and Tirole (1991, p. 149) if $\left(s_{1}^{N}, s_{2}^{N}, \ldots, s_{n}^{N}\right)$ is an NE of the static game, then the open-loop strategies $\sigma_{i}^{*}=\left(s_{i}^{N}, s_{i}^{N}, \ldots \ldots s_{i}^{N}, \ldots.\right) i=1,2, \ldots, n$ are an SPNE of the repeated game when there are no bankruptcy considerations. Since no player is bankrupt in these actions, the strategies indeed conform to an SPNE of the dynamic game.

(ii) Let $\left(\tilde{s}^{1}, \tilde{s}^{2}, \ldots, \tilde{s}^{t}, \ldots.\right)$ be the sequence of action profiles with the desired properties. Consider the following strategy for a generic player, say $i$. At time 1 play the action $\tilde{s}_{i}^{1}$. At time $\tau=2,3, \ldots, t, \ldots$ if the history only includes actions profiles $\left(\tilde{s}^{1}, \tilde{s}^{2}, \ldots, \tilde{s}^{\tau-1}\right)$ play $\tilde{s}_{i}^{\tau}$. In any other case play $s_{i}^{N}$. It is clear that such strategies yield the desired sequence of actions. In addition, by the usual reasoning 
such strategies are an SPNE when $\delta$ is sufficiently close to one.

The above observation requires that the set of $\mathrm{BF}$ actions and the NE of the static game have a non-empty intersection. For instance, in Example 1 when the two firms are different, firm 2 does not produce in the Cournot equilibrium so this equilibrium is BF. In Example 2, Cournot equilibrium outputs are $(2.5,2.5)$ and thus they are BF. ${ }^{4}$

Our first result corresponds to an asymptotic result for two firms which is independent on both demand and costs conditions. The result states that, when $\delta$ is sufficiently close to one, any NE of the dynamic game yields $B F$ action profiles in each period. Denoting monopoly profits for firm $i$ as $\pi_{i}^{M}$, we have the following:

Proposition 3. Let $n=2$. Suppose that $\left(s_{1}^{1}, s_{2}^{1}, \ldots, s_{1}^{t}, s_{2}^{t}, \ldots\right)$ is a sequence of actions yielded by an NE such that there is an $\epsilon>0$ with $\pi_{i}\left(s^{t}\right)+\epsilon \leq \pi_{i}^{M}$ for all $t=1,2, \ldots, i=1,2$. Then, when $\delta$ tends to $1,\left(s_{1}^{t}, s_{2}^{t}\right)$ is BF for all $t$.

Proof. Suppose that in period $t,\left(s_{1}^{t}, s_{2}^{t}\right)$ is not $B F$. Thus, one firm can bankrupt the other. Suppose, without loss of generality, it is firm 2. Consider the following strategy for firm 2. In period $t$ choose an action $\tilde{s}_{2}$, that drives firm 1 into bankruptcy and choose the output corresponding to monopoly thereafter. In this case, the continuation payoff for firm 2 is

$$
(1-\delta)\left(\pi_{2}\left(s_{1}^{t}, \tilde{s}_{2}\right)+\delta \pi_{2}^{M}+\delta^{2} \pi_{2}^{M}+\ldots .\right) .
$$

The continuation payoff at $t$ for the sequence $\left(s_{1}^{1}, s_{2}^{1}, \ldots, s_{1}^{t}, s_{2}^{t}, \ldots\right)$ is:

$$
(1-\delta)\left(\pi_{2}\left(s^{t}\right)+\delta \pi_{2}\left(s^{t+1}\right)+\delta^{2} \pi_{2}\left(s^{t+2}\right)+\ldots . .\right)
$$

By the definition of an NE,

$$
\pi_{2}\left(s^{t}\right)+\delta \pi_{2}\left(s^{t+1}\right)+\delta^{2} \pi_{2}\left(s^{t+2}\right)+\ldots \geq \pi_{2}\left(s_{1}^{t}, \tilde{s}_{2}\right)+\delta \pi_{2}^{M}+\delta^{2} \pi_{2}^{M}+\ldots
$$

or

$$
\pi_{2}\left(s^{t}\right)-\pi_{2}\left(s_{1}^{t}, \tilde{s}_{2}\right) \geq \delta\left(\pi_{2}^{M}-\pi_{2}\left(s^{t+1}\right)\right)+\delta^{2}\left(\pi_{2}^{M}-\pi_{2}\left(s^{t+2}\right)\right)+\ldots . \geq \delta \epsilon+\delta^{2} \epsilon+\ldots=\delta \frac{\epsilon}{1-\delta}
$$

Clearly, when $\delta \rightarrow 1$, the above inequality is impossible, contradicting that we were in an NE.

\footnotetext{
${ }^{4}$ More general conditions under which $\mathrm{NE}$ and $\mathrm{BE}$ have a non-empty intersection are available under request.
} 
This result can be extended to $n$ firms in the following sense. For a sufficiently large $\delta$, in an NE no firm can drive to bankruptcy all other firms with an action as long as for all firms payoffs in the NE are less than the monopoly payoff. However, the generalization of Proposition 3 for $n>2$ is not possible. The difficulty is that, after, say, firm $i$ is driven bankrupt by an action of firm $j$, the strategies of the other firms can be anything. The following example shows that when $n>2$ it is possible to sustain as SPNE allocations that are not BF.

Example 4. Let us consider a market with three firms and an inverse demand function $p\left(\sum_{i=1}^{3} x_{i}\right)=$ $a-\sum_{i=1}^{3} x_{i}$. Firms have constant average cost such that $c_{1}=c_{2}<c_{3}$ with $a>c_{1}$ and $c_{3}>$ $\left(2 c_{1}+a\right) / 3$. The best reply functions are:

$$
x_{i}=\max \left\{0, \frac{a-c_{i}-\sum_{i \neq j} x_{j}}{2}\right\}, i=1,2,3 .
$$

The unique Cournot equilibrium is $x_{1}^{C}=x_{2}^{C}=\frac{a-c_{1}}{3}$ and $x_{3}^{C}=0$.

Now suppose that firms 1 and 2 collude and maximize their joint profits taking into account the best reply of firm 3. Thus, denoting $z \equiv x_{1}+x_{2}$, the equilibrium is found by $\max \left(a-z-x_{3}-c_{1}\right) z$ over (3.5) for $i=3$ or $\max \left(a-z+c_{3}-2 c_{1}\right) z$. This yields

$$
x_{1}^{J}=x_{2}^{J}=\frac{a-2 c_{1}+c_{3}}{6}, x_{3}^{J}=\frac{a-2 c_{3}+c_{1}}{3} .
$$

Thus, assuming $\left(a+c_{1}\right) / 2>c_{3}$, firm 3 produces a positive output in the collusive outcome. Assuming also that $\left(a+c_{3}-2 c_{1}\right)>\sqrt{2}\left(a-c_{1}\right),{ }^{5}$ guarantees that in this outcome the profits of all firms are strictly larger than in the Cournot equilibrium.

Now consider the following strategies: $x_{i}^{1}=x_{i}^{J} i=1,2,3$. If $x_{i}^{t-r}=x_{i}^{J}$ for all $r \in\{1,2, . ., t-1\}$ and $i \in\{1,2,3\}$, then $x_{i}^{t}=x_{i}^{J}$. Otherwise $x_{i}^{t}=x_{i}^{C}$.

For $\delta$ sufficiently close to 1 , the previous strategies constitute an SPNE that generates actions $x_{i}^{t}=x_{i}^{J}$ for all $t=1,2, \ldots, T, \ldots$ and $i=1,2,3$. The proof is virtually identical to that for observation 3.

The previous example shatters our hope of extending Proposition 3 to $n>2$. Thus, in what follows we turn to characterize Nash equilibria under different assumptions on the technology. This additional information will provide us with important clues for characterizing the equilibrium set.

\footnotetext{
${ }^{5}$ Note that the conditions $\left(2 c_{1}+a\right) / 3<c_{3}<\left(a+c_{1}\right) / 2$ and $\left(a+c_{3}-2 c_{1}\right)>\sqrt{2}\left(a-c_{1}\right)$ are compatible for some values of the parameters. In particular for $c_{1}=0, c_{3}=4,5$ and $a=10$.
} 


\subsection{Dynamics with Increasing Average Cost}

We begin by considering the case of Increasing Average Cost under the following extra assumption. ${ }^{6}$

Assumption 2. All firms have an increasing average cost and product is homogeneous, and for any subset $S \subseteq N$, there is a unique $\left(\hat{x}_{1}, \hat{x}_{2}, \ldots, \hat{x}_{s}\right)$ with $\hat{x}_{i} \neq 0$ for all $i \in S$ such that $\pi_{i}\left(\hat{x}_{1}, \hat{x}_{2}, \ldots, \hat{x}_{s}\right)=0$ for all $i \in S$.

It is easy to find sufficient conditions on demand and cost functions such that Assumption 2 holds. In what follows, whenever we use the notation $\left(\hat{x}_{1}, \hat{x}_{2}, \ldots, \hat{x}_{s}\right)$ for any $S$ we refer to the vector described in the Assumption 2. We now adapt the standard definition of a minimax payoff to the case in which actions are constrained to be $B F$.

We denote by $x_{-i} \in \mathbb{R}_{+}^{n-1}$ a vector of actions for each firms except firm $i$. Let $B_{-i}$ be the set of actions $x_{-i}$ such that there exist an action for firm $i$ such that $\left(x_{i}, x_{-i}\right)$ is $B F$ (since the set of $B F$ action profiles is not empty, this set is well defined). For each $x_{-i} \in B_{-i}$, let $B_{i}\left(x_{-i}\right)=\left\{x_{i} \mid\right.$ $\left(x_{i}, x_{-i}\right)$ is $\left.B F\right\}$. The minimax $B F$ payoff for firm $i$ is defined as:

$$
\pi_{i m}=\min _{x_{-i} \in B_{-i}} \max _{x_{i} \in B_{i}\left(x_{-i}\right)} \pi_{i}\left(x_{i}, x_{-i}\right) .
$$

The following lemma gives us a handier expression for the minimax $B F$ payoff under Assumption 2 .

Lemma 1. Under Assumption 2, the minimax BF payoff is

$$
\pi_{i m}=\max _{x_{i} \in\left[0, \hat{x}_{i}\right]} \pi_{i}\left(x_{i}, \hat{x}_{-i}\right)
$$

where $\left(\hat{x}_{i}, \hat{x}_{-i}\right)>>(0,0)$ is such that $\pi_{j}\left(\hat{x}_{i}, \hat{x}_{-i}\right)=0$ for all $j$.

Proof. Since the payoff of firm $i$ is affected by the aggregate output of the other firms but not by which firm is producing it, the worse situation for firm $i$ in the BF set is the one with the maximal aggregate output in the set $B_{-i}$. Note that for all $x_{-i} \in B_{-i}$ firm $i$ cannot bankrupt any other firm. We denote by $\bar{B}_{-i}$ the set of all pairs $x_{-i}$ such that firm $i$ cannot bankrupt any of the other firms. Notice that $B_{-i} \subseteq \bar{B}_{-i}$. The set $\bar{B}_{-i}$ is characterized by the following inequalities:

$$
\pi_{j}\left(\bar{x}_{i}, x_{-i}\right) \geq 0, \text { for all } j \neq i,
$$

\footnotetext{
${ }^{6}$ The case of constant returns is the boundary between increasing and decreasing average cost curves. Thus this case is indeed exceptional and we will devote no attention to it.
} 
where $\bar{x}_{i}=\bar{x}_{i}\left(x_{-i}\right)>0$ is such that

$$
\pi_{i}\left(\bar{x}_{i}, x_{-i}\right)=0
$$

The set $\bar{B}_{-i}$ is compact. Thus, the $\max _{x_{-i} \in \bar{B}_{-i}} \sum_{j \neq i} x_{j}$ exist. The maximum is reached at $\hat{x}_{-i}>>$ 0 such that $\pi_{j}\left(\hat{x}_{i}, \hat{x}_{-i}\right)=0$ for all $j$. By Assumption $2,\left(\hat{x}_{i}, \hat{x}_{-i}\right)$ is well defined and is a $B F$ action profile. Thus $\left(\hat{x}_{i}, \hat{x}_{-i}\right) \in B_{-i}$. Therefore, $\hat{x}_{-i}=\arg \max _{x_{-i} \in B_{-i}} \sum_{j \neq i} x_{j}$. Since $B_{i}\left(\hat{x}_{-i}\right)=\left[0, \hat{x}_{i}\right]$, the minimax $B F$ payoff is reduced to:

$$
\pi_{i m}=\max _{x_{i} \in\left[0, \hat{x}_{i}\right]} \pi_{i}\left(x_{i}, \hat{x}_{-i}\right)
$$

and the proof is completed.

In the next proposition we show that, for a sufficiently large $\delta$, no SPNE of the dynamic game can give any firm a payoff lower than its minimax $B F$ payoff. To formally introduce the result, we need the two following lemmas. The proofs are in the Appendix.

Lemma 2. Let $\left(x_{1}, . ., x_{n}\right)$ be such that all firms have non negative profits. If $\sum_{j \neq i} x_{j}>\sum_{j \neq i} \hat{x}_{j}$, then firm $i$ can bankrupt some of the other firms.

Lemma 3. Let $S$ and $S^{\prime}$ be such that $S \subset S^{\prime}$, and let $k \in S$. The minimax BF payoff for firm $k$ in the economy $S\left(\pi_{k m}^{S}\right)$ is larger than the minimax BF payoff for firm $k$ in the economy $S^{\prime}\left(\pi_{k m}^{S^{\prime}}\right)$.

Proposition 4. There exists $\delta^{\prime} \in(0,1)$ such that for all $\delta \in\left(\delta^{\prime}, 1\right), \pi_{i}<\pi_{i m}$ cannot be sustained in any SPNE.

Proof. We prove the proposition by induction on the number of firms. We start by showing that the statement is true when there are only two firms in the market.

With two firms, the minimax BF payoff is

$$
\pi_{i m}=\min _{x_{j} \in\left[0, \hat{x}_{j}\right]} \max _{x_{i} \in\left[0, \hat{x}_{i}\right]} \pi_{i}\left(x_{i}, x_{j}\right) .
$$

Thus, firm $i$ could have achieved at least $\pi_{i m}$ if $x_{j}^{t} \in\left[0, \hat{x}_{j}\right]$ for all $t$, irrespective of $\delta$. Therefore, if $\pi_{i}<\pi_{i m}$ happens in equilibrium, $x_{j}^{t}>\hat{x}_{j}$ must hold for some $t$. We show that if this is the case, the continuation payoff for $i$ at $t$ in equilibrium, $P_{i}^{t}$, must be such that $P_{i}^{t} \geq \delta \pi_{i}^{M}$, where $\pi_{i}^{M}$ is the monopoly profit. Suppose that $P_{i}^{t}<\delta \pi_{i}^{M}$; since $x_{j}^{t}>\hat{x}_{j}$, firm $i$ can bankrupt firm $j$ retaining non-negative profits, and can achieve a monopoly profit in every period from $t+1$. Under this 
situation, the continuation payoff for firm $i$ will be greater than $\delta \pi_{i}^{M}$. However, $\delta \pi_{i}^{M}>P_{i}^{t}$, which contradicts the notion that we are in equilibrium. Thus, $P_{i}^{t} \geq \delta \pi_{i}^{M}$. Since $\delta \pi_{i}^{M} \rightarrow \pi_{i}^{M}$ as $\delta \rightarrow 1$, and $\pi_{i m}<\pi_{i}^{M}, \pi_{i}$ must exceed $\pi_{i m}$ at some point as $\delta$ increases, which concludes the proof for $n=2$.

Suppose that the proposition is true for $n-1$ firms. We show that it is true for $n$ firms.

By 3.8, firm $i$ could have achieved at least $\pi_{i m}$ if $\sum_{j \neq i} x_{j}^{t} \leq \sum_{j \neq i} \hat{x}_{j}$ for all $t$ irrespective of $\delta$. Therefore, if $\pi_{i}<\pi_{i m}$ occurs in equilibrium, $\sum_{j \neq i} x_{j}^{t}>\sum_{j \neq i} \hat{x}_{j}$ for some $t$, and if this is the case, at $t$ firm $i$ could bankrupt some other firm. Suppose, without lost of generality, that firm $i$ can bankrupt firm $k$. Since we start with an equilibrium, whatever the strategies that support this equilibrium are, they should be such that in the subgame in which all firms but $k$ survive, they constitute a Nash equilibrium. We denote by $\pi_{i}^{N-k}$ a possible payoff that firm $i$ can obtain in the equilibrium of the subgame with all firms but $k$. Let $\Pi_{i}^{N-k}$ the set of all those possible payoffs. Let us see that the continuation payoff for $i$ at $t$ in equilibrium, $P_{i}^{t}$, must be such that $P_{i}^{t} \geq \delta \pi_{i}^{N-k}$ for some $\pi_{i}^{N-k} \in \Pi_{i}^{N-k}$. Suppose that $P_{i}^{t}<\delta \pi_{i}^{N-k}$ for all $\pi_{i}^{N-k} \in \Pi_{i}^{N-k}$. If this is the case, firm $i$ can deviate in period $t$ by bankrupting firm $k$ and retaining non-negative profits and conforming with the initial strategy thereafter. Thus, firm $i$ can achieve $\pi_{i}^{N-k}$ profits in every period from $t+1$. Under this situation, the continuation payoff for firm $i$ will be greater that $\delta \pi_{i}^{N-k}$. However, $\delta \pi_{i}^{N-k}>P_{i}^{t}$, which contradicts the notion that we are in equilibrium. Thus, $P_{i}^{t} \geq \delta \pi_{i}^{N-k}$ for some $\pi_{i}^{N-k} \in \Pi_{i}^{N-k}$. By the induction hypothesis, for $\delta$ sufficiently large, $\pi_{i}^{N-k} \geq \pi_{i m}^{N-k}$, where $\pi_{i m}^{N-k}$ is the minimax BF payoff when the firms in the market are $N \backslash\{k\}$. Since $\delta \pi_{i m}^{N-k} \rightarrow \pi_{i m}^{N-k}$ and $\pi_{i m}^{N-k}>\pi_{i m}^{N}, \pi_{i}$ must exceed $\pi_{i m}^{N}$ at some point as $\delta$ increases, which concludes the proof.

Next we give sufficient conditions for the existence of an SPNE in our framework. We say that $\pi_{i}$ is an individually rational $B F$ payoff if $\pi_{i}>\pi_{i m}$. An individually rational $B F$ vector payoff $\left(\pi_{i}\right)_{i \in N}$ is feasible if there exist a $B F$ action profile $\left(x_{1}, \ldots, x_{n}\right)$ such that $\pi_{i}=\pi_{i}\left(x_{1}, x_{2}, . ., x_{n}\right)$ for all $i \in N$.

Proposition 5. Let $\pi=\left(\pi_{i}\right)_{i \in N}$ be a feasible and individually rational BF payoff vector. Then, there exists $\delta^{\prime}$ such that for all $\delta \in\left(\delta^{\prime}, 1\right), \pi$ is the average payoffs in some SPNE.

Proof. The proof is given by constructing an equilibrium which is originally proposed by Fudenberg and Maskin (1986). Let $\left(\pi_{i}\right)_{i \in N}$ be feasible and individually rational BF payoff vector. 
By the definition of feasibility, there is a $B F$ action profile $\left(x_{1}, . ., x_{n}\right)$ such that

$$
\pi_{i}=\pi_{i}\left(x_{1}, . ., x_{n}\right) \text { for } i \in N
$$

Suppose each firm takes this $x_{i}, i \in N$ in each period if no deviation has occurred, but all $i \in N$ choose $\hat{x}_{i}$, for $T$ periods once one of them unilaterally deviates from the equilibrium path. If no one deviates during these $T$ periods, then firms go back to the original path. Otherwise, if one of them deviates, then firms restart this phase for $T$ more periods. We prove that this strategy actually constitutes an SPNE.

First consider a deviation from the equilibrium path. Suppose firm $i$ takes $x_{i}^{\prime} \neq x_{i}$ in some period, say period t. By the one-stage-deviation principle (e.g. Fudenberg and Tirole, 1991, p.110), a deviation is profitable if and only if firm $i$ could profit by deviating from the original strategy in period $t$ only and conforming thereafter. Therefore, firm $i$ can benefit by deviation if and only if $\exists x_{i}^{\prime}$ such that

$$
\begin{aligned}
& (1-\delta) \pi_{i}\left(x_{i}^{\prime}, x_{-i}\right)+(1-\delta)\left(\delta+. .+\delta^{T}\right) \pi_{i}\left(\hat{x}_{i}, \hat{x}_{-i}\right)+\delta^{T+1} \pi_{i} \\
& =(1-\delta) \pi_{i}\left(x_{i}^{\prime}, x_{-i}\right)+\delta^{T+1} \pi_{i}>\pi_{i}=(1-\delta)\left(1+\delta+\ldots+\delta^{T}\right) \pi_{i}+\delta^{T+1} \pi_{i} \\
& \Leftrightarrow(1-\delta)\left\{\left(\pi_{i}\left(x_{i}^{\prime}, x_{-i}\right)-\pi_{i}\right)-\left(\delta+\ldots+\delta^{T}\right) \pi_{i}\right\}>0
\end{aligned}
$$

Let $\Delta_{i}=\max _{x_{i}^{\prime}} \pi_{i}\left(x_{i}^{\prime}, x_{-i}\right)-\pi_{i}$ and choose $T$ such that

$$
\Delta_{i}<T \pi_{i}
$$

Note that the left hand side of (3.14) is weakly less than

$$
(1-\delta)\left\{\Delta_{i}-\left(\delta+\ldots+\delta^{T}\right) \pi_{i}\right\}
$$

This term is non-positive when $\delta$ is close to 1 . Therefore, (3.14) cannot be satisfied for such $T$. By the same argument as above, firm $i$ can benefit by deviating from the mutual minmax phase if and only if $\exists x_{i}^{\prime \prime}$

$$
\begin{aligned}
& (1-\delta) \pi_{i}\left(x_{i}^{\prime \prime}, \hat{x}_{-i}\right)+(1-\delta)\left(\delta+\ldots+\delta^{T}\right) \pi_{i}\left(\hat{x}_{i}, \hat{x}_{-i}\right)+\delta^{T+1} \pi_{i} \\
& >(1-\delta)\left(1+\delta+\ldots+\delta^{T-1}\right) \pi_{i}\left(\hat{x}_{i}, \hat{x}_{-i}\right)+\delta^{T} \pi_{i}
\end{aligned}
$$

which can be written as:

$$
\pi_{i}\left(x_{i}^{\prime \prime}, \hat{x}_{-i}\right)>\delta^{T} \pi_{i}
$$


Note that $\pi_{i}\left(x_{i}^{\prime \prime}, \hat{x}_{-i}\right) \leq \max _{x_{i} \in\left[0, \hat{x}_{i}\right]} \pi_{i}\left(x_{i}, \hat{x}_{-i}\right)=\pi_{i m}$. Since $\pi_{i}>\pi_{i m}$ by assumption. This implies that (3.18) never holds when $\delta$ is close to 1 .

Thus, both on and off the equilibrium paths, there is no profitable deviation when $\delta$ is sufficiently close to 1. Since we can always construct the above equilibrium for arbitrary $\pi$ as long as it is a feasible and individually rational BF payoff vector, the proof is complete.

Note that Propositions 3, 4 and 5, (almost) characterize the SPNE set for two firms and increasing average costs. ${ }^{7}$ However if $n>2$ we can support non BF actions as equilibria as long as they yield payoffs above the minimax BF payoff. In the following proposition we give conditions for this to occur. For simplicity, we work out the case of $n=3$, even though our results can be extended to any $n>3$ at cost of introducing some additional notation. We define $\pi_{i m}^{i j}$ as the minimax BF payoff of firm $i$ when only firms $i$ and $j$ are in the market.

Proposition 6. Let $\left(x_{1}, x_{2}, x_{3}\right)$ be a non BF action profile such that $\pi_{i}\left(x_{1}, x_{2}, x_{3}\right)>\pi_{i m}$ for all $i \in\{1,2,3\}$, and $\pi_{i}\left(x_{1}, x_{2}, x_{3}\right)>\pi_{i m}^{i j}$ for all $i, j \in\{1,2,3\}$. Then, there exists $\delta^{\prime}$ such that for all $\delta \in\left(\delta^{\prime}, 1\right), \pi=\left(\pi_{i}\right)_{i \in\{1,2,3\}}$ is the average payoffs in some SPNE.

Proof. Suppose, without loss of generality, that only firm 3 can be bankrupted. Suppose each firm takes $x_{i}, i \in\{1,2,3\}$ in each period but if one of then deviates such that no firm is bankrupt, then firms start to choose $\hat{x}_{i}^{S}, i \in S=\{1,2,3\}$ for $T$ periods. If no one deviates during these $T$ periods, then firms go back to the original path. Otherwise, if one of them deviates in one of this $T$ periods, then firms restart this phase for $T$ more periods. If one firm deviates by bankrupting firm 3, then firm 1 and 2 chose $\hat{x}_{i}^{S \prime}, i \in S^{\prime}=\{1,2\}$ for $T$ periods. If no one deviates during this phase, then firms chose $\left(\bar{x}_{1}, \bar{x}_{2}\right)$ a $B F$ action profile in the market with those two firms such $\pi_{i}\left(x_{1}, x_{2}, x_{3}\right)>\pi_{i}\left(\bar{x}_{1}, \bar{x}_{2}\right)>\pi_{i m}^{i j}$. If one of them deviates from this phase, then firms restart this phase for $T$ more periods.

We show that this strategy actually constitutes an SPNE.

First consider the deviation on the equilibrium path when no firm is bankrupted. Suppose firm $i$ takes $x_{i}^{\prime} \neq x_{i}$ in some period, say period $t$ such that this firm does not bankrupt any other firm. By the one-stage-deviation principle, deviation is profitable if and only if firm $i$ could profit by deviating from the original strategy in period $t$ only and conforming thereafter. Therefore, firm $i$

\footnotetext{
${ }^{7}$ Only the points in the boundary are not considered in these propositions.
} 
can benefit by deviation if and only if $\exists x_{i}^{\prime}$ such that

$$
\begin{aligned}
& (1-\delta) \pi_{i}\left(x_{i}^{\prime}, x_{j}, x_{k}\right)+(1-\delta)\left(\delta+. .+\delta^{T}\right) \pi_{i}\left(\hat{x}_{i}^{S}, \hat{x}_{j}^{S}, \hat{x}_{k}^{S}\right)+\delta^{T+1} \pi_{i} \\
& =(1-\delta) \pi_{i}\left(x_{i}^{\prime}, x_{j}, x_{k}\right)+\delta^{T+1} \pi_{i}>\pi_{i}=(1-\delta)\left(1+\delta+\ldots+\delta^{T}\right) \pi_{i}+\delta^{T+1} \pi_{i} \\
& \Leftrightarrow(1-\delta)\left\{\left(\pi_{i}\left(x_{i}^{\prime}, x_{j}, x_{k}\right)-\pi_{i}\right)-\left(\delta+\ldots+\delta^{T}\right) \pi_{i}\right\}>0 .
\end{aligned}
$$

Let $\Delta_{i}=\max _{x_{i}^{\prime}} \pi_{i}\left(x_{i}^{\prime}, x_{j}, x_{k}\right)-\pi_{i}$ and choose $T$ such that

$$
\Delta_{i}<T \pi_{i}
$$

Note that the left hand side of (3.19) is weakly less than

$$
(1-\delta)\left\{\Delta_{i}-\left(\delta+\ldots+\delta^{T}\right) \pi_{i}\right\}
$$

This term is non-positive when $\delta$ is close to 1 . Therefore, (3.19) cannot be satisfied for such $T$.

Deviations from the mutual minmax phase cannot bankrupt any firm because $\left(\hat{x}_{1}^{S}, \hat{x}_{2}^{S}, \hat{x}_{3}^{S}\right)$ is $B F$. Thus, by the same argument as above, firm $i$ can benefit by deviating from the mutual minmax phase if and only if $\exists x_{i}^{\prime \prime}$

$$
\begin{aligned}
& (1-\delta) \pi_{i}\left(x_{i}^{\prime \prime}, \hat{x}_{j}^{S}, \hat{x}_{k}^{S}\right)+(1-\delta)\left(\delta+\ldots+\delta^{T}\right) \pi_{i}\left(\hat{x}_{i}^{S}, \hat{x}_{j}^{S}, \hat{x}_{k}^{S}\right)+\delta^{T+1} \pi_{i} \\
& >(1-\delta)\left(1+\delta+\ldots+\delta^{T-1}\right) \pi_{i}\left(\hat{x}_{i}^{S}, \hat{x}_{j}^{S}, \hat{x}_{k}^{S}\right)+\delta^{T} \pi_{i}
\end{aligned}
$$

which can be written as:

$$
\pi_{i}\left(x_{i}^{\prime \prime}, \hat{x}_{j}^{S}, \hat{x}_{k}^{S}\right)>\delta^{T} \pi_{i}
$$

Note that $\pi_{i}\left(x_{i}^{\prime \prime}, \hat{x}_{j}^{S}, \hat{x}_{k}^{S}\right) \leq \max _{x_{i} \in\left[0, \hat{x}_{i}\right]} \pi_{i}\left(x_{i}, \hat{x}_{j}^{S}, \hat{x}_{k}^{S}\right)=\pi_{i m}$. Since $\pi_{i}>\pi_{i m}$ by assumption. This implies that (3.23) never holds when $\delta$ is close to 1 .

Now, consider deviations whereby one firm can bankrupt firm 3. Suppose this firm is firm 1. Firm 1 can benefit by deviating if and only if $\exists x_{1}^{\prime}$ that bankrupt firm 3 and such that

$$
\begin{aligned}
& (1-\delta) \pi_{1}\left(x_{1}^{\prime}, x_{2}, x_{3}\right)+(1-\delta)\left(\delta+. .+\delta^{T}\right) \pi_{1}\left(\hat{x}_{1}^{S^{\prime}}, \hat{x}_{2}^{S^{\prime}}\right)+\delta^{T+1} \pi_{1}\left(\bar{x}_{1}, \bar{x}_{2}\right) \\
> & \pi_{i}=(1-\delta)\left(1+\delta+\ldots+\delta^{T}\right) \pi_{i}+\delta^{T+1} \pi_{i} .
\end{aligned}
$$


Since $\pi_{i}>\pi_{1}\left(\bar{x}_{1}, \bar{x}_{2}\right)$. The above inequality is true if and only if

$$
\begin{aligned}
& (1-\delta) \pi_{1}\left(x_{1}^{\prime}, x_{2}, x_{3}\right)+(1-\delta)\left(\delta+. .+\delta^{T}\right) \pi_{1}\left(\hat{x}_{1}^{S^{\prime}}, \hat{x}_{2}^{S^{\prime}}\right) \\
> & (1-\delta)\left(1+\delta+\ldots+\delta^{T}\right) \pi_{i} . \\
\Leftrightarrow & (1-\delta)\left\{\left(\pi_{i}\left(x_{i}^{\prime}, x_{j}, x_{k}\right)-\pi_{i}\right)-\left(\delta+\ldots+\delta^{T}\right) \pi_{i}\right\}>0 .
\end{aligned}
$$

However, bankrupting a firm always has a cost, and therefore, $\pi_{i}\left(x_{i}^{\prime}, x_{j}, x_{k}\right)-\pi_{i}<0$. Thus, the above inequality can never hold.

Deviations from the mutual minmax phase with two firms cannot bankrupt any firm because $\left(\hat{x}_{1}^{S^{\prime}}, \hat{x}_{2}^{S^{\prime}}\right)$ is $B F$. Thus, by the same argument as above, firm 1 (the same argument applies to firm 2) can benefit by deviating from the mutual minmax phase if and only if $\exists x_{i}^{\prime \prime}$

$$
\begin{aligned}
& (1-\delta) \pi_{1}\left(x_{1}^{\prime \prime}, \hat{x}_{2}^{S^{\prime}}\right)+(1-\delta)\left(\delta+\ldots+\delta^{T}\right) \pi_{1}\left(\hat{x}_{1}^{S^{\prime}}, \hat{x}_{2}^{S^{\prime}}\right)+\delta^{T+1} \pi_{1}\left(\bar{x}_{1}, \bar{x}_{2}\right) \\
> & (1-\delta)\left(1+\delta+\ldots+\delta^{T-1}\right) \pi_{1}\left(\hat{x}_{1}^{S^{\prime}}, \hat{x}_{2}^{S^{\prime}}\right)+\delta^{T} \pi_{1}\left(\bar{x}_{1}, \bar{x}_{2}\right) .
\end{aligned}
$$

The previous inequality can be written as:

$$
\pi_{1}\left(x_{1}^{\prime \prime}, \hat{x}_{2}^{S^{\prime}}\right)>\delta^{T} \pi_{1}\left(\bar{x}_{1}, \bar{x}_{2}\right) .
$$

Note that $\pi_{1}\left(x_{i}^{\prime \prime}, \hat{x}_{2}^{S^{\prime}}\right) \leq \max _{x_{1} \in\left[0, \hat{x}_{1}^{S^{\prime}}\right]} \pi_{1}\left(x_{1}, \hat{x}_{2}^{S^{\prime}}\right)=\pi_{1 m}^{12}$. Since $\pi_{1}\left(\bar{x}_{1}, \bar{x}_{2}\right)>\pi_{1 m}^{12},(3.26)$ never holds when $\delta$ is closed to one.

Thus, both on and off the equilibrium paths, there is no profitable deviation when $\delta$ is sufficiently close to 1.

We note that when firms are required to make $v_{i}$ profits in order to be not bankrupted and $v_{i}<0$ this $v_{i}$ can be considered as a part of the cost. In this case, even if we have constant returns to scale, the transformed cost function displays increasing average costs. We now work out an example for two firms with identical constant average cost but different financial constraints. This special case will allow us to illustrate how the set of feasible and individually rational BF payoff vectors changes with the financial constraints, and we show that, in some situations, the symmetric collusive output cannot be sustained as an equilibrium of the dynamic game.

Example 5. Let $n=2, p=\left(3-x_{1}-x_{2}\right), c=1$. Let $\Pi$ be the set of feasible individually rational bankruptcy free payoff vectors. In Figure 4, 5,6 and 7 we represent the set $\Pi$ under different scenarios. In the figures, the interior dot denotes the payoff for the static Cournot equilibrium, 
$\pi_{1}=\pi_{2}=4 / 9$. The dot on the line denotes the payoff in a symmetric collusive outcome whereby firms set a monopoly price and equally divide the share, $\pi_{1}=\pi_{2}=1 / 2$.

(a) If there is no financial constraints, $\Pi$ is the set of feasible individually rational payoff vectors.

$$
\Pi=\left\{\left(\pi_{1}, \pi_{2}\right) \mid \pi_{1}>0, \pi_{2}>0, \pi_{1}+\pi_{2} \leq 1\right\} .
$$

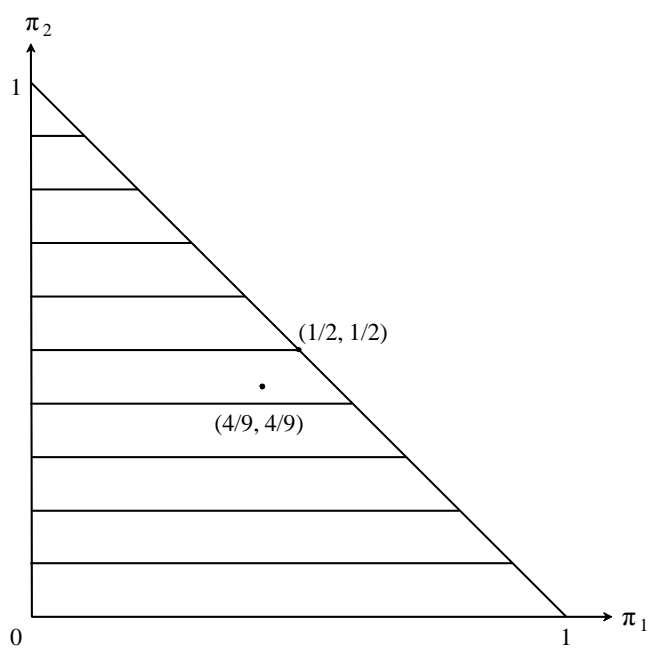

Figure 4

(b) If $v_{1}=v_{2}=-0.5$

$$
\Pi=\left\{\left(\pi_{1}, \pi_{2}\right) \mid \pi_{1}>\pi_{1 m}, \pi_{2}>\pi_{2 m}, \pi_{1}+\pi_{2} \leq 1\right\} .
$$

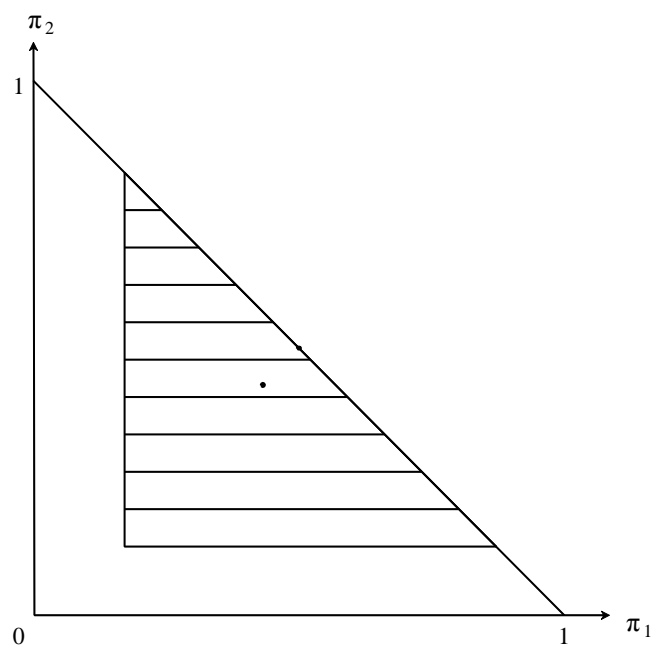

Figure 5

(c) If $v_{1}=-0.25, v_{2}=-1$

$$
\Pi=\left\{\left(\pi_{1}, \pi_{2}\right) \mid \pi_{1}>\pi_{1 m}, \pi_{2}>\pi_{2 m}, \pi_{1}+\pi_{2} \leq 1\right\} .
$$




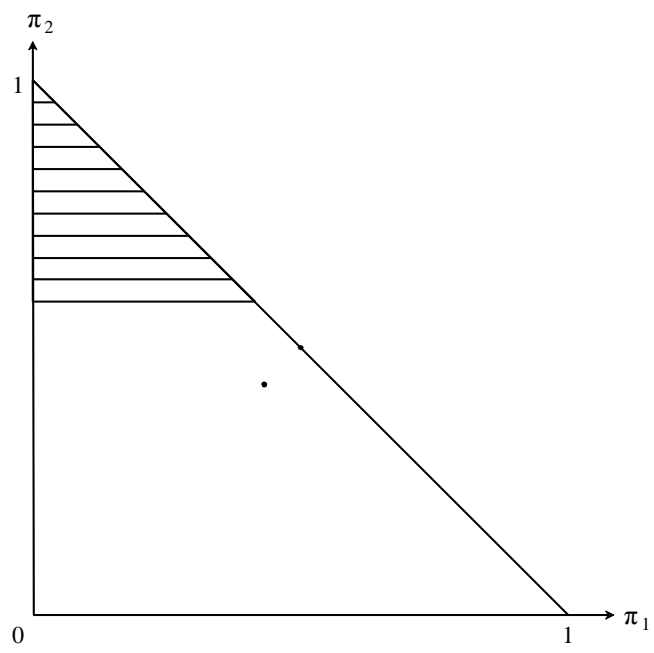

Figure 6

(d) If $v_{1}=-0.01, v_{2}=-0.2$

$$
\Pi=\left\{\left(\pi_{1}, \pi_{2}\right) \mid \pi_{1}>\pi_{1 m}, \pi_{2}>\pi_{2 m}, \pi_{1}+\pi_{2} \leq 1\right\} .
$$

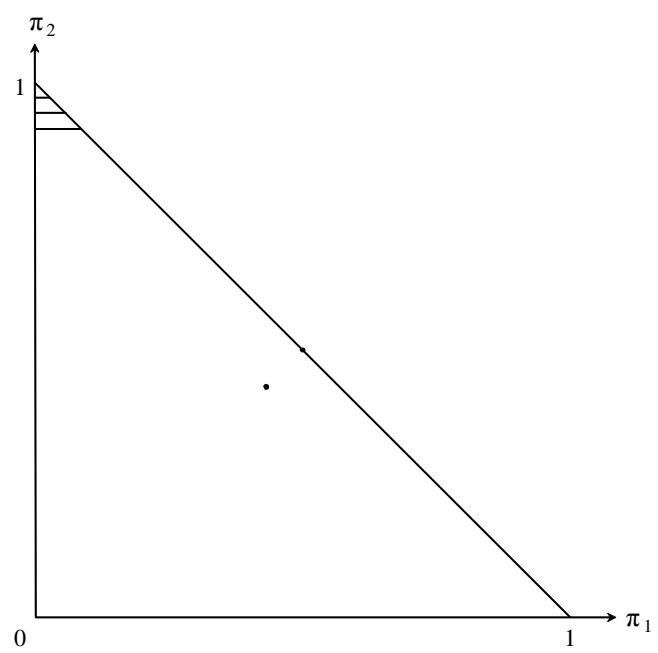

Figure 7

To summarize, Propositions 4 and 5 point out that introduction of financial constraints shrinks the set of equilibrium payoffs. Example 5 shows that, under asymmetric financial constraints, the set of equilibrium payoffs shrinks in favor of a firm that has a larger financial budget. 


\subsection{Dynamics with Decreasing Average Cost}

We address the case of decreasing average costs. We recall that under Assumption 1, only two kind of action profile are $B F$. Action profiles in which there is only one active firm (i.e. those under the heading (i) in Proposition 2) and action profiles in which at least two firms are active and earn zero profits (i.e. those under the heading (ii) in Proposition 2). In the following proposition we show that the $B F$ action profiles with at least two active firms cannot be supported by an NE and we give conditions under which $B F$ action profiles with only one active firm can be supported as NE.

Proposition 7. Under Assumption 1, a BF action profile $\tilde{x}=\left(\tilde{x}_{1}, \tilde{x}_{2}, \ldots, \tilde{x}_{n}\right)$ can be supported as an NE iff: (i) There is only one firm, say $j$, with $\tilde{x}_{j}>0$. (ii) $\tilde{x}_{j}$ limits the entry of all other firms. (iii) $\tilde{x}_{j}$ is a monopoly output for firm $j$.

Proof. Sufficiency. Consider open loop strategies in which all firms play $\left(\tilde{x}_{1}, \tilde{x}_{2}, \ldots, \tilde{x}_{n}\right)$ in each period. Since $\tilde{x}_{j}$ limits the entry of all other firms and it is a monopoly output $\left(\tilde{x}_{1}, \tilde{x}_{2}, \ldots, \tilde{x}_{n}\right)$ is an NE of the one period game and thus these open-loop strategies form, indeed, a NE.

Necessity. Let $\left(\sigma_{1}, \sigma_{2}, \ldots, \sigma_{n}\right)$ be a list of strategies that constitute NE and yields in each period a $B F$ action profile. Suppose that for some period $t$ there are two firms with positive output. Since the action profile is $B F$, by part (ii) in Proposition $2, \pi_{i}\left(x_{1}, . ., x_{n}\right)=0$ and $\partial \pi_{i}\left(x_{1}, . ., x_{n}\right) / \partial x_{i}<0$ for all active firms. Thus, at $t$ firm $i$ can reduces an $\varepsilon$ its output and produce zero in any subsequent period. However, since $\partial \pi_{i}\left(x_{1}, . ., x_{n}\right) / \partial x_{i}<0$, with this strategy firm $i$ makes positive profits, which contradicts the notion that we are in NE. Thus, in a NE, one firm at most is active. The possibility that in NE no firm is active can be discarded because one firm would enter in a period, earn positive profits and produce zero thereafter. Thus, in each period there is only one active firm and (i) above holds. The output of the active firm must deter entry because otherwise a hit and run entry by another firm would be profitable for this firm, so (ii) also holds. Finally, if firm $j$ is not producing a monopoly output, a one period change of output by this firm (continuing with the limit output thereafter) improves the profits of this firm, contradicting the notion that we are in NE.

Our results here give some support to the idea (which underlies the concept of natural monopoly) that under increasing returns only one firm can survive in equilibrium. Indeed, when $n=2$ this is the only allocation that can be sustained as an SPNE. 
It remains to be shown whether non $B F$ action profiles can be sustained as an SPNE. Although we do not have a general answer to this question, in the next proposition we show that action profiles whereby all firms produces a positive quantity cannot be supported as NE.

Let $\tilde{x}=\left(\tilde{x}_{1}, \tilde{x}_{2}, \ldots, \tilde{x}_{n}\right)$ denote a profile of outputs such that $\tilde{x}_{i}>0$ for all $i$.

Proposition 8. Under Assumption 1, when $\delta$ is sufficiently close to 1, there is no NE strategy profile, $\left\{s^{t}\right\}_{t}$, such that there is an $\epsilon>0$ with $\pi_{i}\left(s^{t}\right)+\epsilon \leq \pi_{i}^{M}$ in each $t$, yielding $\tilde{x}$ in a period.

Proof. Suppose there is such strategy profile. Let $j$ be the firm such that $A V C_{j}\left(\tilde{x}_{j}\right) \leq$ $A V C_{i}\left(\tilde{x}_{i}\right)$ for all $i$. Clearly all profits at $\tilde{x}$ must be non-negative.

First, let $\pi_{j}\left(\tilde{x}_{j}, \tilde{x}_{-j}\right)>0$. Let $y$ be such that $\pi_{j}\left(\tilde{x}_{j}+y, \tilde{x}_{-j}\right)=0$. The existence of $y$ is guaranteed by Assumption 1. Now we have that

$$
p\left(y+\sum_{i}^{n} \tilde{x}_{i}\right)=A V C_{j}\left(\tilde{x}_{j}+y\right)<A V C_{j}\left(\tilde{x}_{j}\right) \leq A V C_{i}\left(\tilde{x}_{i}\right),
$$

so all firms except $j$ are ruined and $j$ is a monopolist from this period on. For $\delta$ sufficiently close to 1 , this unilateral change in output increases discounted profits (the same argument as for Proposition 3 can be applied here), which contradicts that the notion that we are in a NE.

Now consider the case where $\pi_{j}\left(\tilde{x}_{j}, \tilde{x}_{-j}\right)=0$. Since $A V C_{j}\left(\tilde{x}_{j}\right) \leq A V C_{i}\left(\tilde{x}_{i}\right)$ for all $i$ and to produce zero is always an option it must be that $A V C_{j}\left(\tilde{x}_{j}\right)=A V C_{i}\left(\tilde{x}_{i}\right)=p\left(\sum_{i=1}^{n} \tilde{x}_{i}\right)$ for all $i$. If $\tilde{x}$ is BF we have shown that it cannot be supported as an NE. If the allocation is not BF, this means that $\exists k$ and a $x_{k}$ such that with the resultant price, $p\left(x_{k}+\sum_{i \neq k} \tilde{x}_{i}\right)$, at least one firm is bankrupted. However, since $A V C_{j}\left(\tilde{x}_{j}\right)=A V C_{i}\left(\tilde{x}_{i}\right) i, j \neq k$ this means that all firms except $k$ can be bankrupted. Thus when $\delta$ is sufficiently close to 1 , firm $k$ has incentives to choose $x_{k}$ and to be a monopolist from this period on. Again, the same argument as for Proposition 3 can be applied here to show that, in this case, the deviation increases discounted profits which contradicts the notion that we are in an NE.

The question arises as to whether the bound on the number of active firms in the previous result is tight. The following example shows that when $n=3$ there are SPNE with two active firms.

Example 6. Suppose that there are three firms with constant marginal costs equal to zero, a fixed cost $K=1000$, and an inverse demand function $p\left(\sum_{i=1}^{3} x_{i}\right)=100-\sum_{i=1}^{3} x_{i}$. Consider the following strategies $^{8}$.

\footnotetext{
${ }^{8}$ These strategies are Markovian in the sense that they only depend on the state, defined as the set of firms.
} 
(S1) For firm 1: in the first period, produce zero output. Thereafter, if firms 2 and 3 exists, produce zero output. If, at least, one of these two firms has disappeared, produce the monopoly output.

(S2) For firms 2 and 3: in the first period, produce the Cournot duopoly output. Thereafter, if the three firms exists, produce the Cournot duopoly output. If one of these two firms has disappeared and firm 1 exists, the remaining firm produces zero output. If one of these two firms has disappeared and firm 1 does not exists, produce the monopoly output. If firm 2 and 3 exist but firm 1 has disappeared, then firm 2 produces the monopoly output and firm 3 produces cero output.

To prove that (S1) and (S2) yield an SPNE, we first note that in this example the following two conditions hold:

(C1) When firms 2 and 3 produce the Cournot duopoly, they obtain positive profits and the best reply by firm 1 is zero. Furthermore, firm 1 cannot bankrupt either firm 2 or firm 3. Note, however, that the Cournot duopoly is not BF.

(C2) When one firm produces the monopoly output, this firm obtains non-negative profits and limits the entry of the other firms.

By the one-stage-deviation principle, a deviation is profitable if and only if firm $i$ can profit by deviating from the original strategy in period t only and conforming thereafter.

We first show that there is no profitable deviation from any subgame in which the three firms exist. Clearly, since firm 1 cannot bankrupt firm 2 or firm 3 when those firms are producing the Cournot duopoly output and the best reply of firm 1 is to produce cero, no deviation can give firm 1 a better payoff. Thus, firm 1 has no incentives to deviate in these subgames. Firms 2 and 3 are completely symmetric in the subgames, so we show that firm 2 has no incentives to deviate; the same argument applies to firm 3. Firm 2 has no incentive to kill firm 3 when they are in a duopoly because it will not enjoy any profits thereafter. Furthermore, firm 2 has not incentives to deviate from the duopoly outcome when the three firms exist.

Second, we show that there is no profitable deviation from any subgame in which two firms exist. When only two firms exist, one produces the monopoly output, which limits the entry of the other firm, so no profitable deviation exists.

Finally, in subgames in which only one firm exists, there are not profitable deviations since that firm is producing the monopoly output. 


\section{Final Remarks}

In this paper we have developed a theory of dynamic competition in which firms may bankrupt each other. We focussed on allocations that are BF in which a firm can bankrupt others only by bankrupting itself. We have characterized BF allocations under decreasing, constant and increasing returns. Finally, we have shown how BF allocations can be sustained as Nash equilibria in a dynamic game. Our concept of BF allowed us to understand the structure of Nash equilibria in the dynamic game. When there are two firms or increasing average costs, BF plays the leading role when players are very patient. However we have shown that allocation other than BF can be sustained as subgame perfect Nash equilibria. ${ }^{9}$

Our results are obtained at the cost of making several simplifications to make the model tractable. For instance, we did not consider coalitions of firms in the definition of BF allocations or refinements of SPNE (such as renegotiation-proof) to get rid of some equilibria. It is likely that these extensions will not qualitatively alter the nature of our results. However, other issues neglected here might affect our conclusions significantly. Among these the following might be of particular importance.

\section{Mixed strategies}

Throughout the paper we have assumed that firms only use pure strategies, but a good way of avoiding bankruptcy might be to use mixed strategies as boxers use random movements to avoid easy hits. We argue that when $n=2$, if the actions played in equilibrium involve a randomization and one of these actions is not $\mathrm{BF}$, for $\delta$ close enough to 1 , the best strategy of the other firm consists in choosing an action that will bankrupt this firm. This is because sooner or later the probability that the action which is not $\mathrm{BF}$ is played is close to 1 so this firm will be ruined and the predating firm will enjoy monopoly profits forever. Thus, in this case the BF set gives us a indication of which type of actions will arise in equilibria, regardless of what kind of strategy is played by the agents. However, in other cases the introduction of mixed strategies might substantially enlarge the set of allocations that might be supported as equilibria of the dynamic game.

\section{No accumulation}

In this paper we focused on actions that bankrupt other firms, but we did not consider the other

\footnotetext{
${ }^{9} \mathrm{BF}$ allocations may also be relevant in other circumstances such as when managers are so risk-averse that they would never choose an allocation by which they can be driven out of business.
} 
side of bankruptcy, namely the funds that might support or deter aggressive strategies (the "deep pocket" argument). Our result when $n=2$ might survive when accumulation is considered. Indeed, suppose as a first approximation that in each period the firms transfer an exogenous quantity of their wealth to next period. Then in each period we can define a BF set that depends on the wealth accumulated by each firm. If in a period the action chosen by, say, firm 1, is not BF, firm 2 may get rid of firm 1 and enjoy monopoly profits forever. When $\delta$ is sufficiently close to 1 , this is optimal for firm 2. In other cases, accumulation of profits might play an important role shaping the NE set as in the model of Rosenthal and Rubinstein (1984). ${ }^{10}$

\section{Credit}

If credit is given on the basis of past performance, the redefinition of the BF set sketched in the previous paragraph can be applied here and credits can be incorporated into the model. However, if credit is given on the basis of future performance, we have a problem because future performance also depends on credit (via the BF constraints), which makes this problem extremely complex. This points to a deep conceptual problem about credit in oligopolistic markets where firms might be bankrupted. This topic should be the subject of future research.

\section{Entry}

In this paper we assumed a given number of competitors. This implies that the disappearance of a firm does not bring a new one in the market. Of course this should not be taken literally. What we mean is that if entry does not quickly follow it makes sense, as a first approximation, to analyze the model with a given number of firms. For instance when $n=2$ and demand and costs are linear, ruining a firm is a good investment even if monopoly last for one period (this example is available under request). In other cases, though, the nature of equilibria will be altered if, for instance, entry immediately follows the ruin of a competitor as in the model of Rosenthal and Spady (1989). ${ }^{11}$

\section{Buying Competitors}

In our model, there is no option to buy a firm. Sometimes it is argued that buying an opponent may be a cheaper and safer strategy than ruining it. We do not deny that buying competitors

\footnotetext{
${ }^{10}$ They characterize a subset of the Nash equilibria assuming that each player regards ruin of the other player as the best possible outcome and his own ruin as the worst possible outcome.

${ }^{11}$ They consider a prisoner's dilemma in continuous time in a market with room for two firms only. When a firm is bankrupted, this firm is immediately replaced by a new entrant. They show that some kind of predatory behavior can arise in equilibrium.
} 
plays an important role in business practices. However, we contend that under the option of buying, ruining a competitor is irrational. First, buying competitors may be forbidden by a regulatory body because of anticompetitive effects. Second, when the owner of a firm sells it to competitors, this does not stop her from creating a new firm and finance it with the money received from selling the old one. In other words, selling a firm is not equivalent to a contract in which the owner commits not to enter into a market again. Thus, bankruptcy may be the only credible way of getting rid of a competitor. Finally, buying and ruining of competitors may complement each other because the acquisition value may depend on the aggressiveness of the buyer in the past; see Burns (1986) for some evidence in the American tobacco industry. Thus, it seems that a better understanding of the mechanism of ruin might help to further enhancement of our understanding of how the buying mechanism works in this case.

Summing up, the model presented in this paper illuminates certain aspects of the equilibrium in oligopolistic markets in which firms may bankrupt each other. We hope that the insights obtained here can be used in further research in this area.

\section{APPENDIX}

Proof of Lemma 2. Given that $\sum_{j \neq i} x_{j}>\sum_{j \neq i} \hat{x}_{j}$, at least for one $k, x_{k}>\hat{x}_{k}$. We show that firm $i$ can bankrupt firm $k$. Suppose, on the contrary, that this is not possible. Let $\tilde{x}_{i}$ be the maximal output for firm $i$ such that $\pi_{i}\left(\tilde{x}_{i}, x_{-i}\right)=0$. Note that $\tilde{x}_{i} \neq 0$, because otherwise, $\sum_{j \neq i} x_{j} \geq$ $\sum_{j} \hat{x}_{j}$ and thus $p\left(\sum_{j \neq i} x_{j}\right) \leq p\left(\sum_{j} \hat{x}_{j}\right)=A V C_{k}\left(\hat{x}_{k}\right)<A V C_{k}\left(x_{k}\right)$, which would imply negative profits for firm $k$. Thus $\tilde{x}_{i} \neq 0$. Then, $p\left(\tilde{x}_{i}+\sum_{j \neq i} x_{j}\right)=A V C_{i}\left(\tilde{x}_{i}\right)$. Since $\sum_{j \neq i} x_{j}>\sum_{j \neq i} \hat{x}_{j}$, $p\left(\tilde{x}_{i}+\sum_{j \neq i} \hat{x}_{j}\right)>A V C_{i}\left(\tilde{x}_{i}\right)$. Since $p\left(\hat{x}_{i}+\sum_{j \neq i} \hat{x}_{j}\right)=A V C_{i}\left(\hat{x}_{i}\right), \tilde{x}_{i}<\hat{x}_{i}$. Since we have supposed that firm $i$ cannot bankrupt firm $k$, then $p\left(\tilde{x}_{i}+\sum_{j \neq i} x_{j}\right) \geq A V C_{k}\left(x_{k}\right)$. However, $A V C_{k}\left(x_{k}\right)>$ $A V C_{k}\left(\hat{x}_{k}\right)$, and $A V C_{k}\left(\hat{x}_{k}\right)=A V C_{i}\left(\hat{x}_{i}\right)>A V C_{i}\left(\tilde{x}_{i}\right)$. Thus, $p\left(\tilde{x}_{i}+\sum_{j \neq i} x_{j}\right)>A V C_{i}\left(\tilde{x}_{i}\right)$ in contradiction with the definition of $\tilde{x}_{i}$. Thus, firm $i$ can bankrupt firm $k$.

Proof of Lemma 3. Let $\hat{x}^{S}=\left(\hat{x}_{i}^{S}\right)_{i \in S}$ be such that $\hat{x}_{i}^{S} \neq 0$ and $\pi_{i}\left(\hat{x}^{S}\right)=0$ for all $i \in S$. Let $\hat{x}^{S^{\prime}}=\left(\hat{x}_{i}^{S^{\prime}}\right)_{i \in S^{\prime}}$ be such that $\hat{x}_{i}^{S^{\prime}} \neq 0$ and $\pi_{i}\left(\hat{x}^{S^{\prime}}\right)=0$ for all $i \in S^{\prime}$. Note first that $\sum_{i \in S} \hat{x}_{i}^{S}<$ $\sum_{i \in S^{\prime}} \hat{x}_{i}^{S^{\prime}}$, and since $A V C_{k}\left(\hat{x}_{k}^{S^{\prime}}\right)=p\left(\sum_{i \in S^{\prime}} \hat{x}_{i}^{S^{\prime}}\right)<p\left(\sum_{i \in S} \hat{x}_{i}^{S}\right)=A V C_{k}\left(\hat{x}_{k}^{S}\right)$ and average cost is 
increasing, then $\hat{x}_{k}^{S^{\prime}}<\hat{x}_{k}^{S}$. Thus, $\sum_{i \in S, i \neq k} \hat{x}_{i}^{S}<\sum_{i \in S^{\prime}, i \neq k} \hat{x}_{i}^{S^{\prime}}$. Therefore,

$$
\pi_{k m}^{S^{\prime}}=\max _{x_{k} \in\left[0, \hat{x}_{k}^{S^{\prime}}\right]} \pi_{k}\left(x_{k}, \sum_{i \in S^{\prime}, i \neq k} \hat{x}_{i}^{S^{\prime}}\right)<\max _{x_{k} \in\left[0, \hat{x}_{k}^{S^{\prime}}\right]} \pi_{k}\left(x_{k}, \sum_{i \in S, i \neq k} \hat{x}_{i}^{S}\right)
$$

because profits are decreasing in the sum of the outputs of the other firms. And finally, since $\hat{x}_{k}^{S^{\prime}}<\hat{x}_{k}^{S}$,

$$
\pi_{k m}^{S^{\prime}}=\max _{x_{k} \in\left[0, \hat{x}_{k}^{S^{\prime}}\right]} \pi_{k}\left(x_{k}, \sum_{i \in S^{\prime}, i \neq k} \hat{x}_{i}^{S^{\prime}}\right) \leq \max _{x_{k} \in\left[0, \hat{x}_{k}^{S}\right]} \pi_{k}\left(x_{k}, \sum_{i \in S, i \neq k} \hat{x}_{i}^{S}\right)=\pi_{k m}^{S}
$$

Thus, $\pi_{k m}^{S^{\prime}}<\pi_{k m}^{S}$. 


\section{References}

[1] Bernanke, B. and M. Gertler (1989). "Agency Costs, Net Worth, and Business Fluctuations". The American Economic Review, 79, 1, 14-31.

[2] Burns, M. R. (1986). "Predatory Pricing and the Acquisition Cost of Competitors". The Journal of Political Economy, 94, 2, 266-296.

[3] Cabral, L. and M. Riordan (1994). "The Learning Curve, Market Dominance, and Predatory Pricing". Econometrica, 62, 1115-1140.

[4] Fudenberg, D. and E. Maskin (1986). "The Folk Theorem in Repeated Games with Discounting or with Incomplete Information". Econometrica, 54: 533-554.

[5] Fudenberg. D. and J. Tirole (1991). Game Theory, MIT Press, Cambridge, MA.

[6] Kawakami, T. and Y. Yoshida (1997), "Collusion under Financial Constraints: Collusion or predation when the discount factor is near one?," Economics Letters, 54: 175-178.

[7] Kiyotaki, N. and J. Moore (1997). "Credit Cycles". The Journal of Political Economy, 105, 2, 211-248.

[8] Masso, J. and A. Neme (1996). "Equilibrium Payoffs of Dynamic Games". International Journal of Game Theory, 25, 4, 437-53.

[9] Milgrom, P. and J. Roberts (1982). "Predation, Reputation, and Entry Deterrence". Journal of Economic Theory, 27, 280-312.

[10] Neyman, A. and S. Sorin (2003, editors). Stochastic Games and Applications. Kluwer Academic Press.

[11] Rosenthal, R. and A. Rubinstein (1984). "Repeated Two-Players Games with Ruin". International Journal of Game Theory, 13, 3, 155-177.

[12] Rosenthal, R. and R. H. Spady (1989). "Duopoly with Both Ruin and Entry". Canadian Journal of Economics, 22, 4, 834-851 
[13] Roth, D. (1996). "Rationalizable Predatory Pricing". Journal of Economic Theory, 68, 380396.

[14] Shapley, L.S. (1953). "Stochastic Games". Proc. Nat. Acad. Science, 39:1095-1100.

[15] Sharfstein, D. and P. Bolton (1990). "A Theory of Predation Based on Agency Problems in Financial Contracting". American Economic Review, 80, 93-106.

[16] Spagnolo, G. (2000), "Stock-Related Compensation and Product-Market Competition". RAND Journal of Economics, 31: 22-42.

[17] Spence, A. M. (1980). "Notes on Advertising, Economies of Scale, and Entry Barriers". The Quarterly Journal of Economics, 95, 3, 493-507. 